\title{
Calcium Dobesilate Modulates PKC $\delta$-NADPH Oxidase- MAPK-NF-KB Signaling Pathway to Reduce CD14, TLR4, and MMP9 Expression during Monocyte-to-Macrophage Differentiation: Potential Therapeutic Implications for Atherosclerosis
}

\author{
Florence Njau * (1) and Hermann Haller
}

Citation: Njau, F.; Haller, H. Calcium Dobesilate Modulates PKC $\delta$-NADPH Oxidase- MAPK-NF- $\kappa B$ Signaling Pathway to Reduce CD14, TLR4, and MMP9 Expression during Monocyte-to-Macrophage Differentiation: Potential Therapeutic Implications for Atherosclerosis. Antioxidants 2021, 10, 1798. https:/ / doi.org/10.3390/antiox10111798

Received: 28 October 2021

Accepted: 8 November 2021

Published: 11 November 2021

Publisher's Note: MDPI stays neutral with regard to jurisdictional claims in published maps and institutional affiliations.

\section{Copyright: (C) 2021 by the authors.} Licensee MDPI, Basel, Switzerland. This article is an open access article distributed under the terms and conditions of the Creative Commons Attribution (CC BY) license (https:/ / creativecommons.org/licenses/by/ $4.0 /)$.
Division of Nephrology, Hannover Medical School, 30625 Hannover, Germany; haller.hermann@mh-hannover.de * Correspondence: Florence.Njau@gmx.de

\begin{abstract}
Monocyte-to-macrophage differentiation results in the secretion of various inflammatory mediators and oxidative stress molecules necessary for atherosclerosis pathogenesis. Consequently, this differentiation represents a potential clinical target in atherosclerosis. Calcium dobesilate (CaD), an established vasoactive and angioprotective drug in experimental models of diabetic microvascular complications reduces oxidative stress and inhibits inflammation via diverse molecular targets; however, its effect on monocytes/macrophages is poorly understood. In this study, we investigated the anti-inflammatory mechanism of CaD during phorbol 12-myristate 13-acetate (PMA)-induced monocyte-to-macrophage differentiation in in vitro models of sepsis (LPS) and hyperglycemia, using THP-1 monocytic cell line. CaD significantly suppressed CD14, TLR4, and MMP9 expression and activity, lowering pro-inflammatory mediators, such as IL1 $\beta, \operatorname{TNF} \alpha$, and MCP-1. The effects of $\mathrm{CaD}$ translated through to studies on primary human macrophages. CaD inhibited reactive oxygen species (ROS) generation, PKC $\delta$, MAPK (ERK1/2 and p38) phosphorylation, NOX2/p47phox expression, and membrane translocation. We used hydrogen peroxide (H2O2) to mimic oxidative stress, demonstrating that $\mathrm{CaD}$ suppressed PKC $\delta$ activation via its ROS-scavenging properties. Taken together, we demonstrate for the first time that CaD suppresses CD14, TLR4, MMP9, and signature pro-inflammatory cytokines, in human macrophages, via the downregulation of PKC $\delta / \mathrm{NADPH}$ oxidase/ROS/MAPK/NF-kB-dependent signaling pathways. Our data present novel mechanisms of how $\mathrm{CaD}$ alleviates metabolic and infectious inflammation.
\end{abstract}

Keywords: atherosclerosis; calcium dobesilate; inflammation; monocyte-macrophage differentiation; oxidative stress; PKC $\delta$

\section{Introduction}

Atherosclerosis is a complex disease with poorly understood mechanisms that contribute to the disease pathogenesis but involve inflammation and oxidative stress. During its pathogenesis, circulating monocytes adhere to endothelial cells and the vessel wall and differentiate into macrophages [1,2].

In particular, monocyte-to-macrophage differentiation associates with high expression of cluster of differentiation (CD) [1,2] and Toll-like Receptor (TLR) [3,4] family members. Moreover, this process also results in the activation of enzyme systems involved in reactive oxygen species (ROS) production (i.e., leukocyte NADPH oxidase) [5], leading to oxidative stress that occurs in parallel with pro-inflammatory molecules [6] and matrix metalloproteinases $[7,8]$ activation. All these processes contribute to atherosclerosis initiation and progression. For example, CD14 macrophages are found in complicated atherosclerotic lesions [2], and atherosclerosis progression delays when Nox2 (an essential component of NADPH oxidase) is inhibited in animal models $[9,10]$. 
Given the above-described elements, strategies to prevent monocytes infiltration and/or differentiation comprise an attractive approach to treat atherosclerosis and other related vascular disorders.

Calcium dobesilate $(\mathrm{CaD})$ is a vasoactive and angioprotective drug having a unique and multi-target mode of action in several experimental studies and different animal models of diabetic microvascular complications. CaD reduces oxidative stress, inflammation, and vascular complications via diverse molecular targets [11-14]. At present, CaD is prescribed to treat microvascular damage-related diseases-diabetic retinopathy and diabetic nephropathy; however, most studies have focused only on endothelial cells.

The effect of $\mathrm{CaD}$ on monocytes/macrophages (the primary source of inflammatory mediators and oxidative stress) and the mechanisms of how CaD modulates monocyte-tomacrophage differentiation remain unknown. To the best of our knowledge, only three studies have addressed the $\mathrm{CaD}$ effects on monocytes/macrophages, including leukocyte adhesion to endothelial cells [11], protection of human peripheral mononuclear cells from oxidation [15], and apoptosis [16].

This study investigated $\mathrm{CaD}$ effects on monocyte-to-macrophage differentiation and its associated inflammation in PMA-, high glucose-, and LPS-treated THP-1 cells. Moreover, we validated our results in primary human M-CSF-derived macrophages. We report for the first time that $\mathrm{CaD}$ downregulates CD14, TLR4, MMP9, and other pro-inflammatory cytokines in THP-1 and primary human macrophages and describe the molecular mechanisms involved-PKC $\delta$-NADPH Oxidase-ROS- MAPK-NF- $\mathrm{B}$ signaling pathways.

\section{Materials and Methods}

\subsection{Materials}

THP-1 (ACC 16) human acute monocytic leukemia cells were obtained from the German Collection of Microorganisms and Cell Cultures (DSMZ) (Braunschweig, Germany). The following compounds were purchased from Sigma-Aldrich (Steinheim, Germany): phorbol 12-myristate 13-acetate (PMA; P8139), lipopolysaccharide (LPS; L2887), glucose (G-7021), calcium dobesilate (CaD; SML0488), diphenyleneiodonium chloride (DPI, a NOX2 inhibitor; D2926), SB203580 (a p38 MAPK inhibitor; S8307), Bay 11-7085 (an NF-kB inhibitor; B5681), H2DCFDA (2' $7^{\prime}$-dichlorofluorescin diacetate, an ROS indicator; D6883), MG132 (proteasome inhibitor; M8699), the phosphatase inhibitors sodium orthovanadate (Na3VO4; S6508), sodium fluoride (NaF; S7920), and PhosSTOPтм (4906845001), and the serine protease inhibitors PMSF (phenylmethanesulfonyl fluoride; P7626) and leupeptin (L851). The MAPK inhibitor (U0126; V1121) was from Promega, (Walldorf, Germany), while the PKC $\delta$ inhibitor rottlerin (sc-3550) and the calpain inhibitor II ALLM (CAS 136632-32-1) were purchased from Santa Cruz (Heidelberg, Germany). $\mathrm{H}_{2} \mathrm{O}_{2}$ was from Carl Roth $\mathrm{GmbH}$, (Karlsruhe, Germany). Antibodies were purchased from Cell Signaling (Frankfurt am Main, Germany), including antibodies against p-ERK1/2 (\#4377), ERK1/2 (\#9102), pP38 (\#4511), P38 (\#9212), pPKC $\delta$-Tyr311 (\#2055), PKC $\delta$ (\#2058), pIкB- $\alpha$ (\#2859), IкB- $\alpha$ (\#4814), CD11b (\#49420), TLR2 (\#12276), MMP9 (\#13667), ß-Tubulin (\#2146), and rabbit- (\#7074) and mouse- (\#7076) IgG-HRP-linked antibodies. Anti-GAPDH (sc-32233), -TLR4 (sc-293072), -pJNK (sc-6254), and -pPKC $\beta I I$ (sc-365463) were from Santa Cruz, (Heidelberg, Germany). BD Biosciences (Heidelberg, Germany): p47phox (\#610355), R\&D Systems (Wiesbaden, Germany), CD14 (MAB3832), and GeneTex (Eching, Germany), CD36 (GTX100642). ELISA kits: IL1 $\beta$ (88-7261-22), TNF $\alpha$ (88-7346-22), and MCP-1 (88-7399-22) were purchased from ThermoFisher Scientific (Darmstadt, Germany).

\subsection{THP-1 Cells Culture, Differentiation, and Treatment}

Cells were cultured in RPMI-1640 (P04-18047; PAN Biotech) supplemented with 20\% fetal bovine serum (FBS), penicillin (100 U/mL), and streptomycin $(100 \mu \mathrm{g} / \mathrm{mL})$, and incubated at $37^{\circ} \mathrm{C}$ in a humidified atmosphere of $5 \% \mathrm{CO}_{2}$. For all experiments, THP-1 cells were seeded at a density of $1 \times 10^{6} / \mathrm{mL}$ and treated for various time points with PMA, LPS, high glucose, or $\mathrm{H}_{2} \mathrm{O}_{2}$. In preliminary studies, we established nontoxic but optimal 
concentrations and time points for the compounds used in the study (data not shown). On the day of treatment, we incubated the cells for $1 \mathrm{~h}$ with the following pharmacological agents: CaD, DPI $(1 \mu \mathrm{M})$ [17], SB203580 $(5 \mu \mathrm{M})$ [18], U0126 $(10 \mu \mathrm{M})$ [18], rottlerin $(250 \mathrm{nM}$ or $2 \mu \mathrm{M})$ [18], Bay 11-7085 (5 $\mu \mathrm{M})$ [19], MG132 (10 $\mu \mathrm{M})$ [20], or ALLM (10 $\mu \mathrm{M})$ [21]. We then stimulated the cells with 30 nM PMA [22], $100 \mathrm{ng} / \mathrm{mL}$ LPS [23], $25 \mathrm{mM}$ glucose [24], or $10 \mathrm{mM} \mathrm{H}_{2} \mathrm{O}_{2}$ [25], for varying time periods. In each case, we compared the inhibitors with their vehicle control to rule out nonspecific cytotoxicity.

\subsection{Primary Monocyte Differentiation and Treatment}

Human peripheral blood mononuclear cells (PBMCs) were isolated from buffy coats (German Red Cross: DRK-Blutspendedienst NSTOB, Springe, Germany) by ficoll gradient centrifugation. According to the supplier's protocol, we purified monocytes from PBMCs using CD14+ beads (Miltenyi Biotech, Bergisch Gladbach, Germany). We cultured the purified monocytes in RPMI-1640 as THP-1cells but with 10\% FBS for $1 \mathrm{~h}$ to allow recovery from stress, and then treated the monocytes with $\mathrm{CaD}(2.5-10 \mu \mathrm{M})$ for $1 \mathrm{~h}$ before inducing differentiation. To induce differentiation, we treated the monocytes with growth factor M-CSF (50 ng/mL) (Peprotech, NJ, USA) for 5 days at $37^{\circ} \mathrm{C}, 5 \% \mathrm{CO}_{2}$. The medium was changed on day 3 during this period. On day 5 , cells were analyzed by immunoblotting or treated with $100 \mathrm{ng} / \mathrm{mL}$ LPS for $24 \mathrm{~h}$ for cytokine production analysis.

\subsection{Assays of Cell Viability and Adhesion}

We first used a CCK-8 kit (Dojindo Molecular Technologies, Munich, Germany) to test the effect of $\mathrm{CaD}$ alone on cellular viability. Briefly, THP1 cells were seeded into 96-well plates, in triplicate, and treated with various concentrations of $\mathrm{CaD}(0,2.5,5,10$, and $20 \mu \mathrm{M})$ for 24,48 , and $72 \mathrm{~h}$ before the addition of CCK-8 solution. We then used a Tecan Microplate Reader (Genios; Männedorf, Switzerland) to measure optical density at $450 \mathrm{~nm}$. Since no toxic effects were detected at all concentrations, subsequent experiments were conducted using $\mathrm{CaD}$ concentrations lower than $20 \mu \mathrm{M}$.

We next investigated cell adhesion by crystal violet staining and bright field microscopy. For crystal violet staining, THP-1 cells were treated for various time points with $30 \mathrm{nM}$ PMA in the presence of 0-10 $\mu \mathrm{M}$ CaD. Non-adherent cells were removed by three gentle rinses with PBS and adherent cells fixed with $4 \%$ paraformaldehyde, washed twice with demineralized water, and $0.1 \%$ crystal violet stain added and incubated at room temperature for $20 \mathrm{~min}$. Stained cells were left to air-dry and eluted with $10 \%$ acetic acid. Absorbance was measured as the optical density (ODs) at $595 \mathrm{~nm}$, using a Tecan microplate reader. For qualitative analysis of monocyte/ macrophage adhesion, phase-contrast images were taken using bright-field microscopy after 48-h stimulation by PMA.

\subsection{Quantitative RT-PCR Analysis}

Total RNA was isolated using RNeasy miniprep kits from Qiagen, Hilden, Germany) and qRT-PCR performed by a LightCycler 96 Real-Time PCR System using Taqman RTPCR with the following Applied Biosystems primers from Dreieich, Germany: PKC $\alpha$ (Hs00176973_m1), PKCß (Hs00176998_m1), PKC (Hs01090047_m1), NOX2 (Hs00166163_m1), MMP9 (Hs00957562_m1), MCP-1/CCL2 (Hs00234140_m1), IL1 $\beta$ (Hs00174097_m1), TNF $\alpha$ (Hs00174128_m1), TLR4 (Hs00152939_m1), TLR2 (Hs00610101_m1), CD14 (Hs02621496_s1), CD36 (Hs00354519_m1). Quantification was carried out using LightCycler 96 software (Roche Diagnostics, Mannheim, Germany), and the amount of RNA was expressed as the expression ratio relative to the housekeeping gene GUSB (Hs00939627_m1). Quantitative PCR for CD11b (forward primer 5'-CAGCCTTTGACCTTATGT-3' and reverse primer $5^{\prime}$-CCTGTGCTGTAGTCGCA-3') and the housekeeping gene Actin B (KSPQ12012, Sigma-Aldrich, Steinheim, Germany) was performed using SBYR Green RT-PCR (Applied Biosystems, Dreieich, Germany). 


\subsection{Cytokine Production}

We used PMA to differentiate THP-1 cells to macrophages in the presence of CaD for $48 \mathrm{~h}$ or M-CSF to differentiate human blood monocytes to macrophages for 5 days. PMA or M-CSF-derived macrophages were then stimulated with $100 \mathrm{ng} / \mathrm{mL}$ LPS. Supernatants from three independent experiments were collected after $24 \mathrm{~h}$ and pooled, and IL1 $\beta$, $\mathrm{TNF} \alpha$, and MCP-1 levels were measured by ELISA, according to the manufacturer's instructions. The cells were lysed for cellular protein content measurement as described below for immunoblotting. Standard curves were then generated by plotting the $\mathrm{pg} / \mathrm{mL}$ concentrations versus absorbance values of the standards and used to quantify the levels of cytokines released by the cells. Detection limits were $2 \mathrm{pg} / \mathrm{mL}, 4 \mathrm{pg} / \mathrm{mL}$, and $7 \mathrm{pg} / \mathrm{mL}$ for IL1 $\beta, T N F \alpha$, and MCP-1, respectively. Final cytokine concentrations $(\mathrm{pg} / \mathrm{mL})$ were normalized to the protein concentration per $\mathrm{ml}$ of each sample and displayed as $\mathrm{pg} / \mathrm{mg}$ of protein in the figures.

\subsection{Determination of Intracellular ROS}

Intracellular reactive oxygen species (ROS) generation was measured by using the cellpermeable indicator $\mathrm{H}_{2}$ DCFDA (Sigma-Aldrich, Steinheim, Germany). Briefly, THP-1 cells were loaded with $5 \mu \mathrm{M} \mathrm{H}_{2}$ DCFDA for $60 \mathrm{~min}$, washed with PBS washed, and pretreated with various $\mathrm{CaD}$ concentrations before stimulation with PMA for different durations. ROS-dependent fluorescence was measured by a microplate reader at excitation $485 \mathrm{~nm}$ and emission $535 \mathrm{~nm}$.

\subsection{MMP9 Gelatin Zymography}

To determine MMP9 enzymatic activity by gelatin zymography, THP-1 cells were treated for $24 \mathrm{~h}$ in a serum-free medium, and $10 \mu \mathrm{L}$ of cell-free conditioned media was collected by centrifugation. The supernatant was then mixed with nonreducing Laemmli sample buffer and $10 \mu \mathrm{L}$ of the mixture was subjected to gel electrophoresis in $10 \%$ SDSPAGE containing $0.1 \%(w / v)$ gelatin. Gels were processed as previously described [26]. The gelatinolytic activity was normalized to the total protein content of the cultured cells.

\subsection{Immunoblotting}

Whole-cell lysates were prepared in complete lysis buffer (RIPA) containing the following inhibitors of proteolysis and dephosphorylation: $1 \mathrm{mM}$ PMSF, $1 \mathrm{mg} / \mathrm{mL}$ aprotinin, $1 \mathrm{mg} / \mathrm{mL}$ leupeptin, $1 \mathrm{mM}$ Na3VO4, $1 \mathrm{mM}$ NaF, PhosSTOP ${ }^{\mathrm{TM}}$ (4906845001; SigmaAldrich, Steinheim, Germany). Following incubation for $10 \mathrm{~min}$ at $4{ }^{\circ} \mathrm{C}$ and centrifugation $(13,000 \times g, 10 \mathrm{~min})$, cells were treated with lysis buffer without detergents, followed by three freeze- $\left(-80{ }^{\circ} \mathrm{C}\right.$ for $\left.1 \mathrm{~h}\right)$ thaw cycles. After another centrifugation $(13,000 \times g, 25 \mathrm{~min})$, soluble cytosolic fractions were removed, and the remaining pellets were treated with complete lysis buffer and sonicated for $15 \mathrm{~s}$. The samples were again centrifuged for 10 min at $4{ }^{\circ} \mathrm{C}$, and the soluble supernatant containing the membrane fraction was removed and saved.

We next subjected proteins to gel electrophoresis through $10-12.5 \%$ polyacrylamide, and electro transferred them to polyvinylidene difluoride membranes (MerckMillipore, Darmstadt, Germany) Burlington, MA, USA). Membranes were blocked with 3\% BSA for $1 \mathrm{~h}$ at room temperature and incubated overnight, at $4{ }^{\circ} \mathrm{C}$, with 1:1000 dilution of each of the following primary antibodies: p-ERK1/2, ERK1/2, pP38, P38, PKC $\delta, \operatorname{pI\kappa B-~} \alpha$, IкB- $\alpha$, CD11b, TLR2, MMP9, and 1:500 dilution of GAPDH, p47phox, TLR4, pJNK, and pPKC $\beta I I$, CD14, and CD36. Secondary antibodies (1:2000), conjugated to horseradish peroxidase, were used to detect protein bands using an enhanced chemiluminescence (ECL) method. Bands were normalized to GAPDH or $\beta$-tubulin as internal controls. The expression of phosphorylated proteins was normalized to total protein levels. 


\subsection{Statistical Analysis}

Data are expressed as means \pm SEMs. The significance of differences between groups was examined using either a Student's $t$-test or one-way ANOVA, as appropriate. $p<0.05$ was considered statistically significant.

\section{Results}

\subsection{Calcium Dobesilate (CaD) Inhibits CD14 and TLR4 Expression during} Monocyte-to-Macrophage Differentiation

PMA-induced THP-1 cell differentiation is a well-accepted in vitro model for studying monocyte-to-macrophage differentiation [27]. Consequently, we first determined the cytotoxic effects of $\mathrm{CaD}$ for 24,48 , and $72 \mathrm{~h}$ on THP- 1 cells, using CCK-8 cell viability assays, showing that $\mathrm{CaD}$ did not cause any detectable cell death in monocytes at the indicated concentrations (Supplementary Figure S1A).

Since PMA treatment induces greater differentiation of THP-1 cells (reflected by the increased adherence and expression of surface markers associated with macrophage differentiation [27]), we studied the effect(s) of $\mathrm{CaD}$ on PMA-induced monocyte-to-macrophage differentiation. We treated THP-1 cells with $30 \mathrm{nM}$ PMA for various time points, in the presence or absence of $\mathrm{CaD}(0-10 \mu \mathrm{M})$, demonstrating that $\mathrm{CaD}$ did not inhibit PMA-induced THP-1 cell adhesion (Supplementary Figure S1B,C).

One feature of monocyte-to-macrophage differentiation is the loss or gain of expression of an array of genes/proteins. Consequently, we analyzed the effect of $\mathrm{CaD}$ on the expression of molecular markers of macrophage differentiation, namely CD11b, CD14, CD36, TLR2, and TLR4. As expected, PMA increased CD36, CD11b, and CD14 expression (Figure $1 \mathrm{~A}-\mathrm{C}$ ). Although $\mathrm{CaD}$ did not affect $\mathrm{CD} 36$ and $\mathrm{CD} 11 \mathrm{~b}$ expression during PMA-induced differentiation, it significantly decreased CD14 expression in a timeindependent (Figure 1C) and dose-dependent manner (Figure 1D,E). Moreover, CaD significantly downregulated TLR4 expression at $72 \mathrm{~h}$ treatment but not TLR2 (Figure 2A,B). CaD dose-dependently downregulated TLR4, but not TLR2, expression (Figure 2C,D). These results suggest that $\mathrm{CaD}$ selectively inhibits certain aspects of monocyte-to-macrophage differentiation and inflammation. Elevated expression and activity of CD14, TLR2, and TLR4 correlate with advanced atherosclerotic lesions, followed by plaque rupture and myocardial infarction $[2,3,28]$. Hence, we speculate that $\mathrm{CaD}$ may alter or improve some aspects of atherosclerosis, although further studies are required to elaborate on this point.

\subsection{CaD Inhibits Inflammation during Monocyte-to-Macrophage Differentiation}

Besides monocyte adhesion and expression of common surface markers during monocyte-to-macrophage differentiation, various inflammatory cascades are evoked during the differentiation process. CD14 and TLR4 facilitate detection of bacterial lipopolysaccharide (LPS); consequently, CD14 and TLR4 knockout mouse macrophages have impaired NF- $\mathrm{KB}$ pathway activation, resulting in deficient LPS-induced IL6 and TNF $\alpha$ production [29-31]. Hence, CaD-mediated CD14 and TLR4 inhibition in THP-1 macrophages could explain why $\mathrm{CaD}$ inhibited NF- $\mathrm{KB}$ activation and the release of its downstream products-IL1 $\beta$, IL6, and TNF $\alpha$, in LPS-treated rat models of systemic inflammation [32]. In this study, we investigated the effect of CaD on TNF $\alpha$, IL1 $\beta$, and MCP- 1 expression during PMA induced monocyte-to-macrophage differentiation; CaD significantly decreased the expression of these cytokines, the optimal time point for all cytokines being $48 \mathrm{~h}$ (Figure 3A-D). CaD dose-dependently decreased IL1 $\beta$ expression, but $10 \mu \mathrm{M}$ was the most effective concentration that inhibited all the pro-inflammatory cytokines expression (Figure 3E,F). 
A

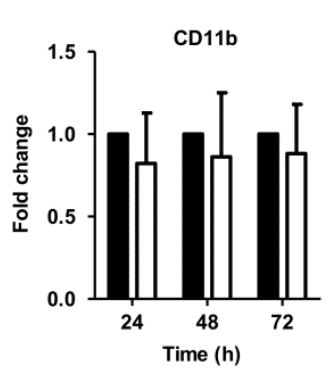

B

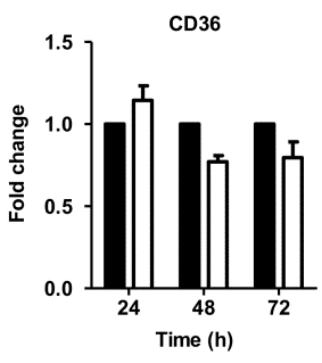

C

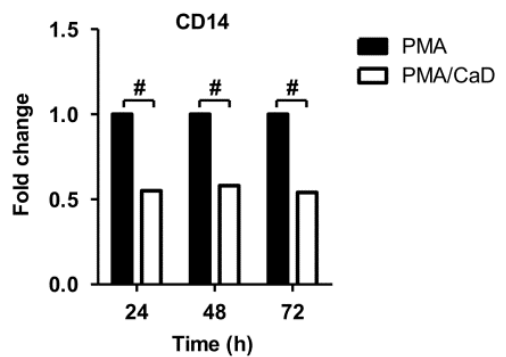

D

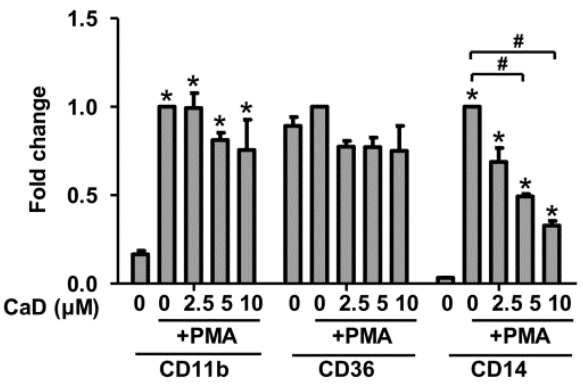

E



Figure 1. Calcium dobesilate (CaD) inhibits PMA-induced CD14 expression. THP-1 monocytes were pretreated with $10 \mu \mathrm{mol} / \mathrm{L} \mathrm{CaD}$ for $1 \mathrm{~h}$, followed by stimulation with PMA $(30 \mathrm{nmol} / \mathrm{L})$ for various time points $(\mathbf{A}-\mathbf{C})$, or treated with various concentrations $(0-10 \mu \mathrm{mol} / \mathrm{L})$ of $\mathrm{CaD}$ for $1 \mathrm{~h}(\mathrm{D}, \mathrm{E})$ followed by PMA treatment for $72 \mathrm{~h}$. Transcript levels of the indicated genes were measured by quantitative RT-PCR (A-D), and protein levels measured by Western blotting (E). $\Delta$, fold-change normalized to PMA only $(n=3-4$, mean \pm SEM. ${ }^{*} p<0.05$ vs. no treatment, ${ }^{\#} p<0.05$ vs. PMA only, Student's $t$-test (A-C), or one-way ANOVA (D)). The Western blot represents one from at least three independent experiments.

A

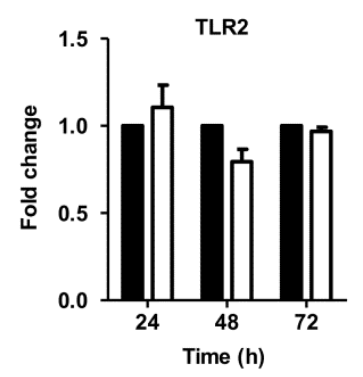

C

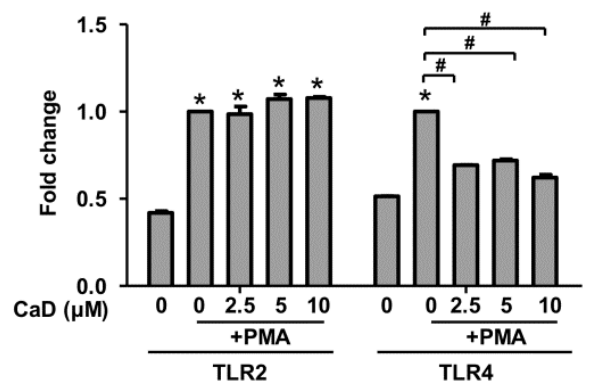

B

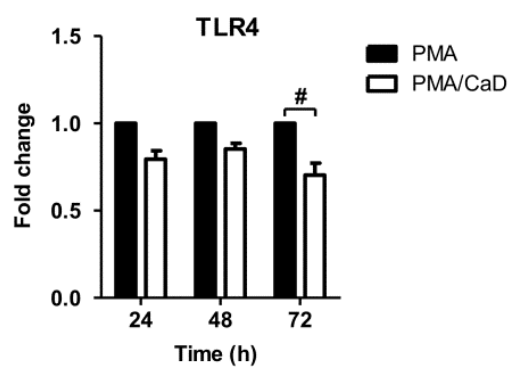

D

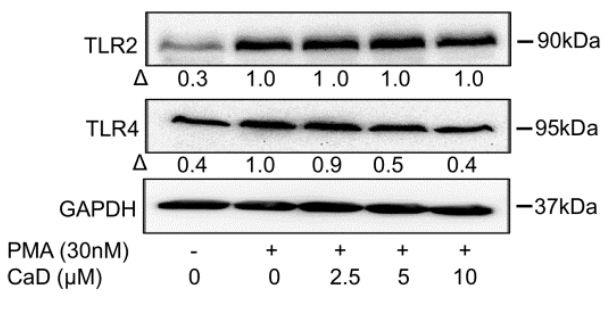

Figure 2. CaD on TLR4 expression during monocyte-to-macrophage differentiation. THP-1 monocytes were pretreated 
with $10 \mu \mathrm{mol} / \mathrm{L}$ of $\mathrm{CaD}$ for $1 \mathrm{~h}$ followed by stimulation with PMA (30 nmol/L) for various time points (A,B), or THP-1 monocytes were treated with various concentrations $(0-10 \mu \mathrm{mol} / \mathrm{L})$ of $\mathrm{CaD}$ for $1 \mathrm{~h}(\mathrm{C}-\mathrm{D})$ followed by PMA treatment for $72 \mathrm{~h}$. TLR2 and TLR4 transcripts (A-C) and protein levels (D) were measured by quantitative RT-PCR and Western blotting, respectively. $\Delta$, fold-change normalized to PMA only $\left(n=3-4\right.$, mean $\pm \mathrm{SEM} .{ }^{*} p<0.05$ vs. no treatment, ${ }^{\#} p<0.05$ vs. PMA only, Student's $t$-test $(\mathbf{A}, \mathbf{B})$, or one-way ANOVA $\left.(\mathbf{C})\right)$. The Western blot represents one from at least three independent experiments.

A

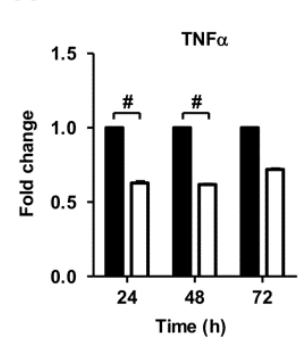

B

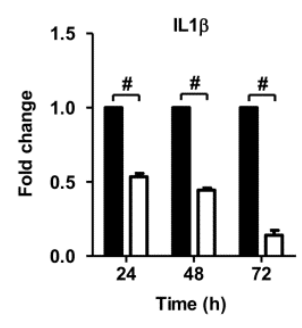

C

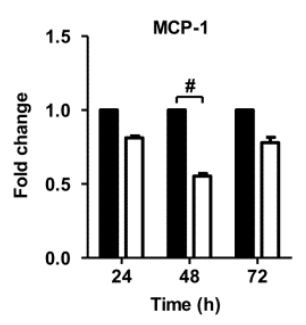

D

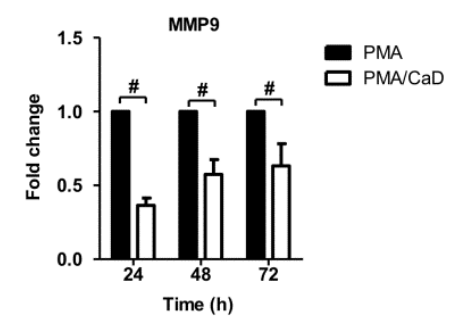

E


Figure 3. CaD inhibits PMA-induced inflammation during PMA-induced monocyte-to-macrophage differentiation. THP-1 monocytes were pretreated with $\mathrm{CaD}(10 \mu \mathrm{mol} / \mathrm{L})$ for $1 \mathrm{~h}$ followed by stimulation with PMA (30 nmol/L) for various time points (A-D), or THP-1 monocytes were treated with various CaD concentrations $(0-10 \mu \mathrm{mol} / \mathrm{L})$, followed by PMA treatment for $48 \mathrm{~h}(\mathrm{E}, \mathrm{F})$. TNF $\alpha, \mathrm{IL}-1 \beta, \mathrm{MCP}-1$, and MMP9 transcript levels were measured by quantitative RT-PCR, and MMP9 protein levels and activity were measured by Western blotting and gelatin zymography, respectively. $\Delta$, fold-change normalized to PMA only ( $n=3-4$, mean \pm SEM. ${ }^{*} p<0.05$ vs. no treatment, ${ }^{*} p<0.05$ vs. PMA only, Student's $t$-test (A-D), or one-way ANOVA (E)). The Western blots represent one from at least three independent experiments.

Macrophage-derived matrix metalloproteases (MMPs) are highly expressed in atherosclerotic plaques and implicated in plaque rupture. Because MMP-9 is one of the key regulators of vascular complications, we studied the effect of PMA on MMP9 expression and activity during monocyte-to-macrophage differentiation. Treatment with CaD inhibited MMP9 expression time-independently (Figure 3D) and dose-dependently (Figure 3E,F). Gelatin zymography is widely used to study gelatinase activation; however, this technique has some pitfalls due to the complexity of the activation process and the inherent limitations of SDS-PAGE, which make identification of active species by gelatin zymography not straightforward, especially if one cannot achieve a good band separation. This study could not delineate the inactive $92 \mathrm{kDa}$ and the active $83 \mathrm{kDa}$ species by gelatin zymography (Figure 3F). However, we demonstrated the presence of both MMP9 species by immunoblotting. Additionally, unlike other MMPs, which are constitutively expressed, MMP9 tends to be inducible by growth factors and inflammatory stimuli; thus, $\mathrm{CaD}$ treatment inhibited MMP9 expression and production. Given the importance of inflam- 
mation in atherosclerosis pathogenesis, our data suggest $\mathrm{CaD}$ as a promising inhibitor of atherosclerosis development and progression.

3.3. The Effect of CaD Is Not Limited to PMA-Induced Monocyte-to-Macrophage Differentiation and Inflammation: Effects of LPS and High Glucose Stimulation

Based on the observation that CaD downregulated CD14 and TLR4 expression during monocyte-to-macrophage differentiation and that CD14 and TLR4 are important in detecting bacterial LPS, we asked whether CaD could inhibit LPS-induced CD14 and TLR4 expression in THP-1 cells. As depicted in Supplementary Figure S2A,B, CaD inhibited LPS-induced CD14 (mRNA), TLR4, and MMP9 expression. We did not detect CD14 protein expression by immunoblotting, possibly because THP-1 cells express low CD14 levels [27].

Since THP-1 cells express low CD14 levels, they are less responsive to LPS treatment [27]. To investigate the effect of LPS and CaD on the expression of inflammatory molecules, we differentiated THP-1 cells to macrophages with PMA in the presence of $\mathrm{CaD}$ for $48 \mathrm{~h}$, treated the macrophages with LPS for $24 \mathrm{~h}$, and measured the expression of representative pro-inflammatory molecules by ELISA and quantitative RT-PCR. Macrophages treated with LPS in the presence of CaD expressed significantly lower IL1 $\beta$, $\mathrm{TNF} \alpha$, and MCP-1 (Figure 4B,C), in agreement with a previous study where CaD reduced pro-inflammatory cytokine production in a rat model of sepsis [32].

In a previous study, a herbal extract named Baihu decoction, which has hypoglycemic and antioxidant effects, significantly inhibited a CD14/TLR4/NF-kB pathway, and its associated inflammation, in a type 2 diabetic mouse model [33]. We hypothesized that based on its effect on CD14 and TLR4 expression, CaD could exert a similar mechanism in diabetic models. As illustrated in Supplementary Figure S3, CaD downregulated the expression of CD14 and TLR4, as well as MMP9, IL1 $\beta$, TNF $\alpha$, and MCP-1, in THP-1 cells cultured in high glucose for $48 \mathrm{~h}$ (to mimic chronic hyperglycemia).

\subsection{CaD Modulates Primary Human Monocyte-to-Macrophage Differentiation and Inflammation}

Although THP-1 cells are a human cell line, they are immortalized monocytic leukemia. So we looked to translate our results to primary human macrophages, using in vitro differentiation of monocytes. Specifically, isolated human monocytes were cultured with MCSF (50 ng/mL) and various CaD concentrations. CaD significantly inhibited CD14, TLR4, and MMP9 protein expression than the M-CSF only treated macrophages in a concentrationdependent manner (Figure 4A). Finally, we wanted to study the effects of CaD on CD14 and TLR4 inflammatory signaling for the differentiated primary macrophages when stimulated with LPS (100 ng/mL) for $24 \mathrm{~h}$. As a readout, we measured the levels of pro-inflammatory cytokines (IL-1 $\beta, \mathrm{TNF} \alpha$, and MCP-1). In agreement with the decreased CD14 and TLR4 expression due to $\mathrm{CaD}$, we observed a significant reduction in all the cytokines tested in response to LPS (Figure 4D). Therefore, the effects of CaD during PMA-induced THP-1 differentiation translate through to human primary macrophage function.

\subsection{Signaling Pathways Affected by CaD during Monocyte-to-Macrophage Differentiation}

We next sought to determine the molecular mechanisms by which $\mathrm{CaD}$ inhibits monocyte-to-macrophage differentiation and inflammation, especially as it is dependent on the protein kinase $C$ and MAPK pathways because PMA is a potent PKC activator and MAPK is downstream of PKC [34]. PMA treatment significantly upregulated PKC $\delta$ expression but weakly increased PKC $\alpha$ and PKC $\beta$ II at the gene level (Figure 5A). Moreover, PMA significantly increased PKC $\delta$ and $\mathrm{pPKC} \beta \mathrm{II}$ phosphorylation (Figure 5B). We did not detect PKC $\alpha$ protein by immunoblotting, likely due to its low expression in THP-1 cells [27]. THP-1 cells treatment with CaD, during differentiation, did not affect PKC $\alpha$ and PPKC $\beta I$ expression, but $\mathrm{CaD}$ significantly reduced $\mathrm{PKC} \delta$ activation (Figure 5A,B), suggesting that $\mathrm{CaD}$ specifically inhibits the PKC $\delta$-dependent signaling pathway during PMA-induced monocyte-to-macrophage differentiation. 
A

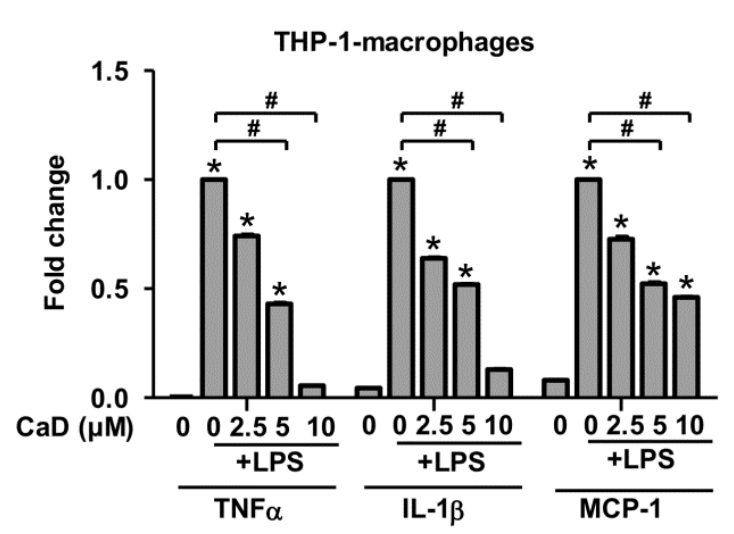

B

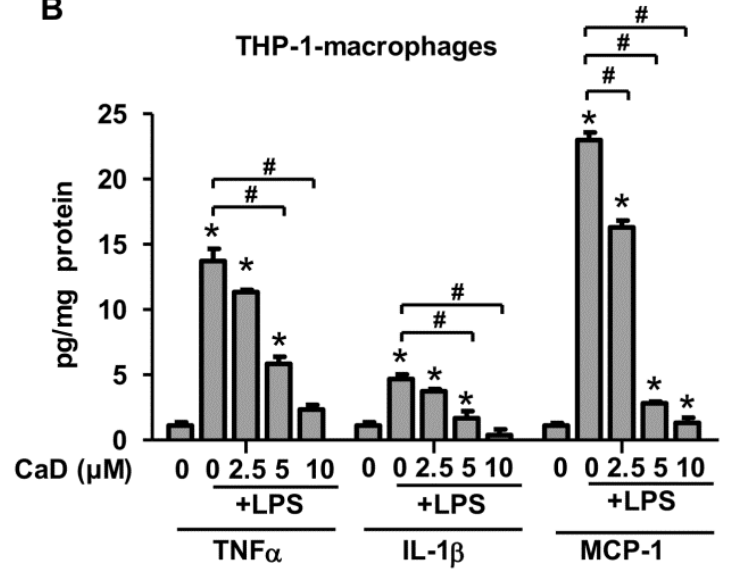

C
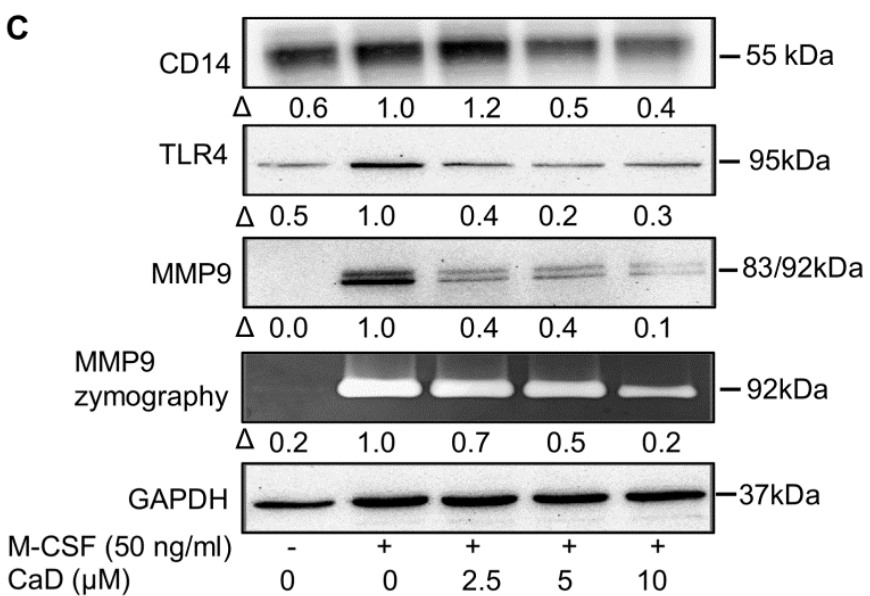

D (i)

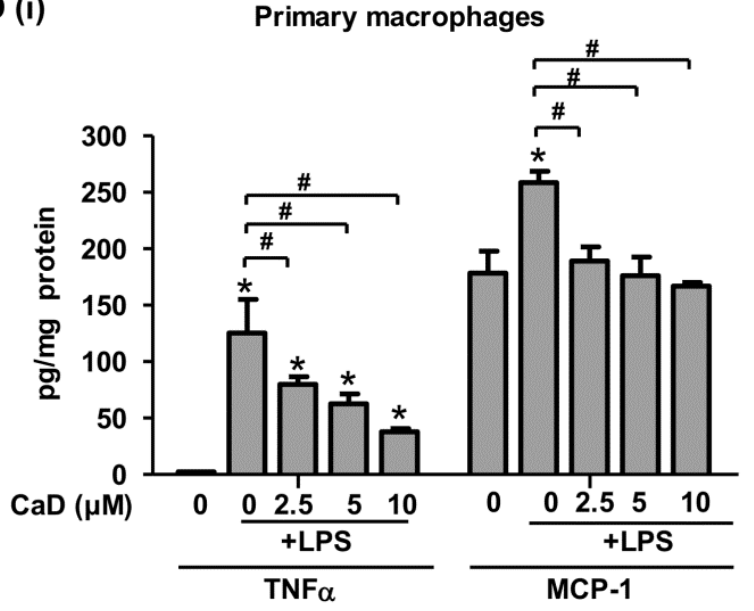

D (ii)

Primary macrophages



Figure 4. CaD inhibits primary human monocyte-to-macrophage differentiation and LPS-induced inflammation. Primary human monocytes were treated with various CaD concentrations $(0-10 \mu \mathrm{mol} / \mathrm{L})$ for $1 \mathrm{~h}$ followed by M-CSF $(50 \mathrm{ng} / \mathrm{mL})$ treatment for 5 days (A). Protein levels and MMP9 activity were measured by Western blotting and gelatin zymography, respectively. THP-1 cells and primary human monocytes were differentiated into macrophages in the presence of various $\mathrm{CaD}$ concentrations $(0-10 \mu \mathrm{mol} / \mathrm{L})$ for $48 \mathrm{~h}$ and 5 days, respectively (B-D). Macrophages were then stimulated with LPS (100 ng/mL) for $24 \mathrm{~h}$. TNF $\alpha$, IL1 $\beta$, and MCP-1 transcript levels (B) were measured by quantitative RT-PCR, and protein levels $(\mathbf{C}, \mathbf{D})$ in the conditioned media were measured by ELISA $(\mathbf{B}) . \Delta$, fold-change normalized to PMA only $(n=3$, mean \pm SEM. ${ }^{*} p<0.05$ vs. no LPS, ${ }^{\#} p<0.05$ vs. LPS only, one-way ANOVA). 
A

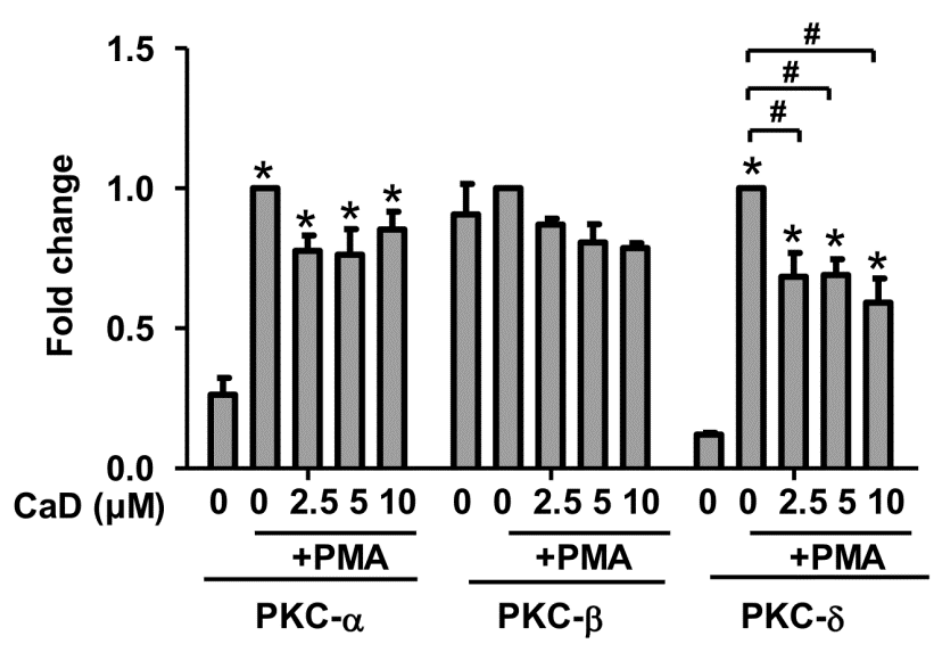

B
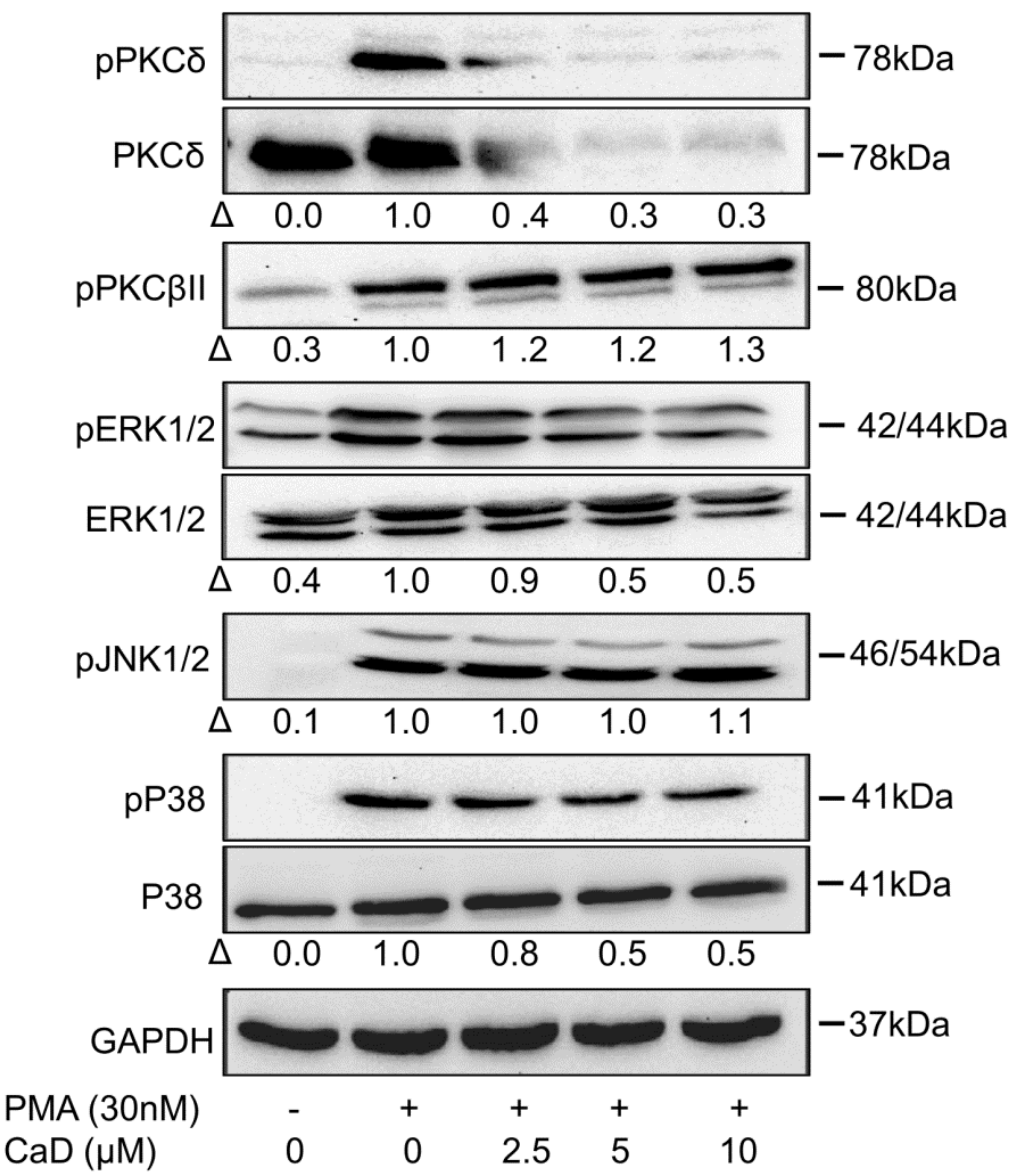

Figure 5. Effect of $\mathrm{CaD}$ on PKC $\delta$-MAPK signaling during PMA-induced monocyte-to-macrophage differentiation. THP-1 monocytes were pretreated with various concentrations $(0-10 \mu \mathrm{mol} / \mathrm{L})$ of $\mathrm{CaD}$ for $1 \mathrm{~h}$, followed by PMA treatment for $24 \mathrm{~h}$ (A) or $30 \mathrm{~min}$ (B). PKC $\alpha$, PKC $\beta I I$, and PKC $\delta$ transcript levels (A) were measured by quantitative RT-PCR, and phosphorylation of PKC and MAPK pathway components (B) was measured by Western blotting. $\Delta$, fold-change normalized to PMA only $(n=3$, mean \pm SEM. ${ }^{*} p<0.05$ vs. no treatment, ${ }^{\#} p<0.05$ vs. PMA only, one-way ANOVA). The Western blots represent one from at least three independent experiments. 
Furthermore, $\mathrm{CaD}$ inhibited ERK1/2 and $\mathrm{p} 38$ phosphorylation induced by PMA treatment (Figure 5B), but not JNK1/2 phosphorylation. These results suggest that $\mathrm{CaD}$ preferentially inhibits ERK1/2 and P38-related pathways.

In addition to PMA, LPS and high glucose are known to activate PKC $\delta$ and MAPK [35-38]. Accordingly, we investigated the effect of $\mathrm{CaD}$ under LPS and high glucose treatment of THP1 cells, finding that CaD significantly downregulated the activation of PKC $\delta$, ERK1/2, and p38 (Supplementary Figure S4A,B). However, we did not detect phosphorylation of PKC $\delta$ by immunoblotting (even at time points ranging from $5 \mathrm{~min}$ to $48 \mathrm{~h}$ ), possibly because LPS and high glucose more weakly induce PKC phosphorylation than PMA.

\subsection{CaD Inhibits Monocyte-to-Macrophage Differentiation and Inflammation via PKC $\delta$, MAPK Pathway}

To determine whether the effect of CaD on PKC $\delta$ is necessary to inhibit CD14, TLR4, MMP9, and pro-inflammatory cytokine expression, we inhibited PKC $\delta$ (rottlerin) in the PMA-THP-1 model. Figure 6 indicates that, compared to rottlerin, CaD likewise significantly downregulated CD14, TLR4, MMP9, TNF $\alpha$, IL1 $\beta$, and MCP-1 expression, suggesting that $\mathrm{CaD}$ inhibits monocyte-to-macrophage differentiation by inhibiting PKC $\delta$ activation.

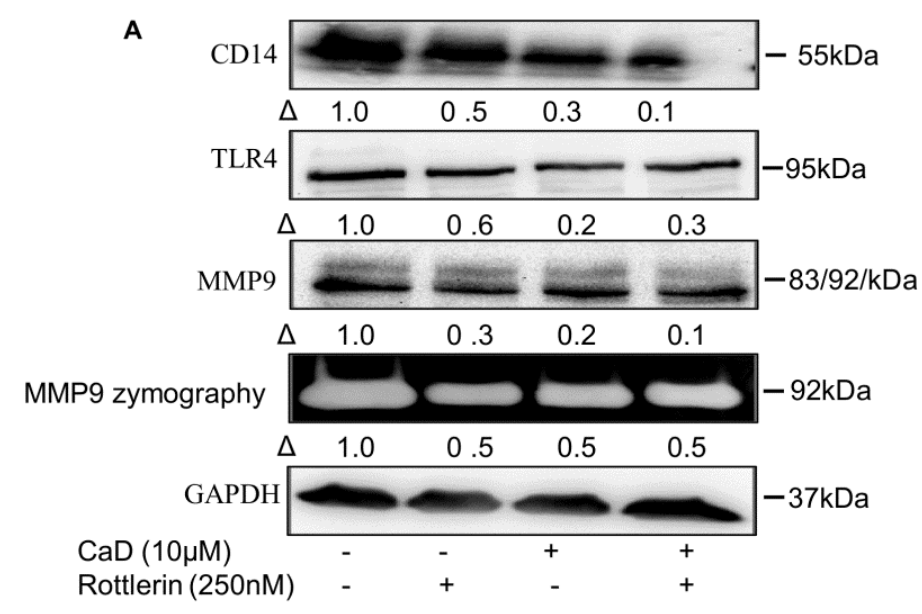

B (i)

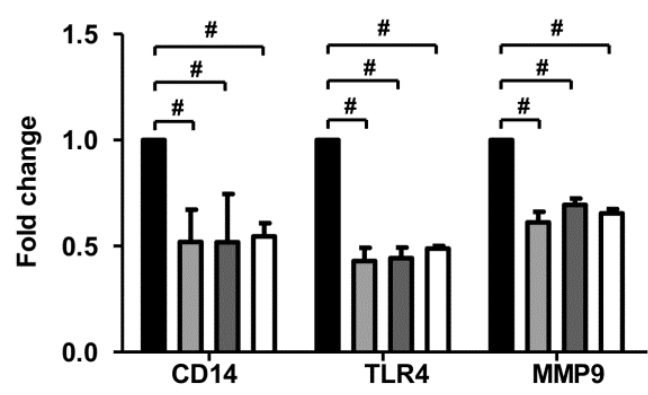

B (ii)

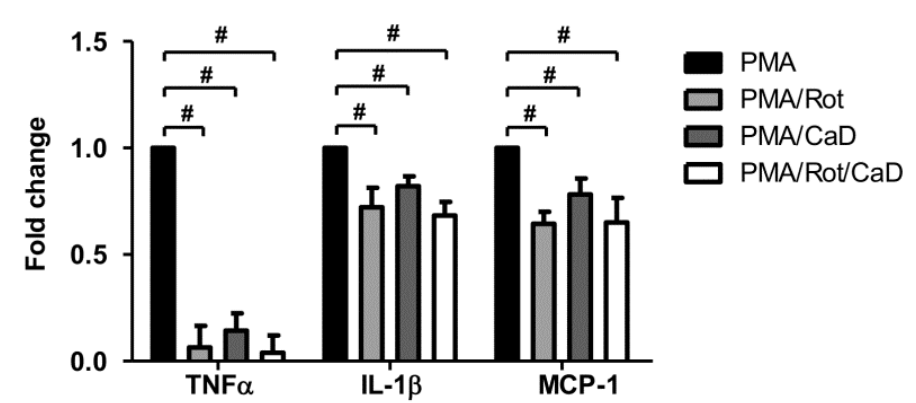

Figure 6. Inhibition of monocyte-to-macrophage differentiation and inflammation by CaD involves PKC $\delta$-dependent signaling. THP-1 monocytes were pretreated with the PKC $\delta$ inhibitor rottlerin (Rot) for $1 \mathrm{~h}$, followed by CaD for $1 \mathrm{~h}$, and then treated with PMA $(30 \mathrm{nmol} / \mathrm{L})$ for $72 \mathrm{~h}$. The differentiation and inflammation marker expression were measured by Western blotting (A), MMP9 activity measured by gelatin zymography, and transcript levels (B) measured by quantitative RT-PCR. $\Delta$, fold-change normalized to PMA only ( $n=3$, mean \pm SEM. ${ }^{*} p<0.05$ vs. PMA only, one-way ANOVA). The Western blot represents one from at least three independent experiments.

Moreover, inhibiting MAPK downregulates CD14, TLR4, MMP9, and inflammatory marker expression [39-41]; we, therefore, inhibited ERK1/2 (U0126) and p38 (SB203580) in the PMA THP-1 cell model in the presence or absence of CaD. Like CaD treatment, both 
MAPK inhibitors significantly inhibited CD14 and TLR4, MMP9, IL1 $\beta$, TNF $\alpha$, and MCP-1 expression (Figure 7). Put together, our findings indicate that PKC $\delta$, ERK1/2, and p38 are the key pathways that $\mathrm{CaD}$ targets to inhibit monocyte-to-macrophage differentiation and inflammation.

A (i)

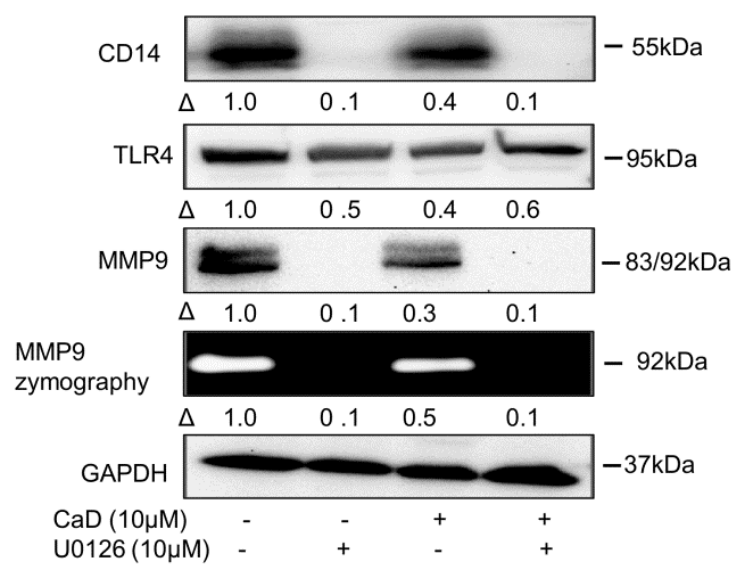

A (ii)

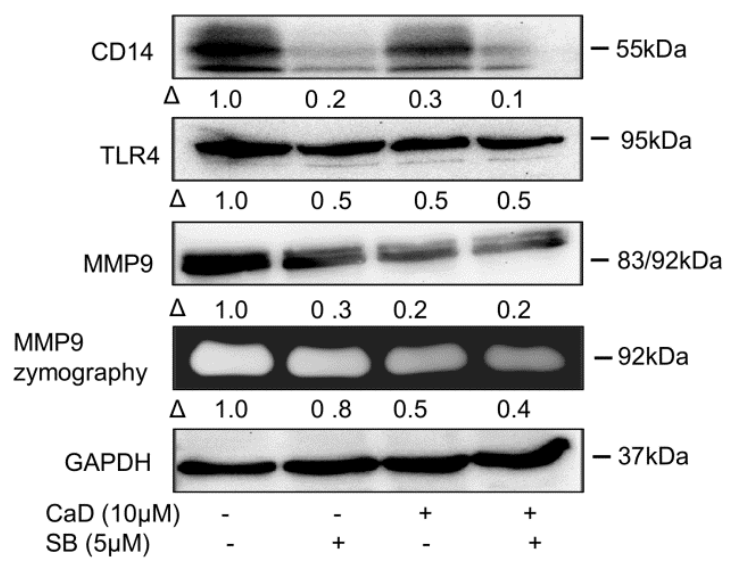

B (i)

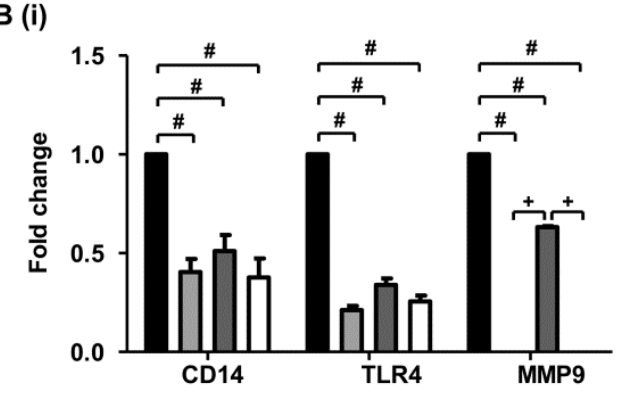

C (i)

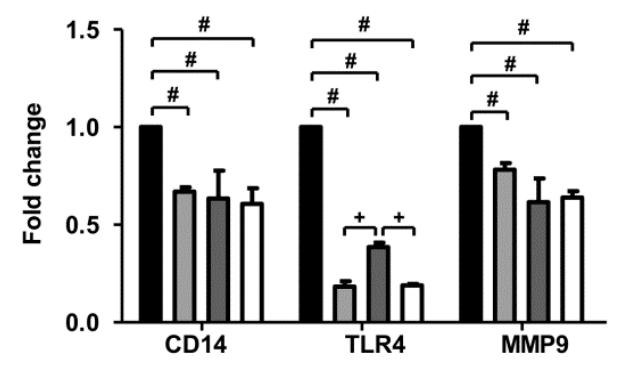

B (ii)

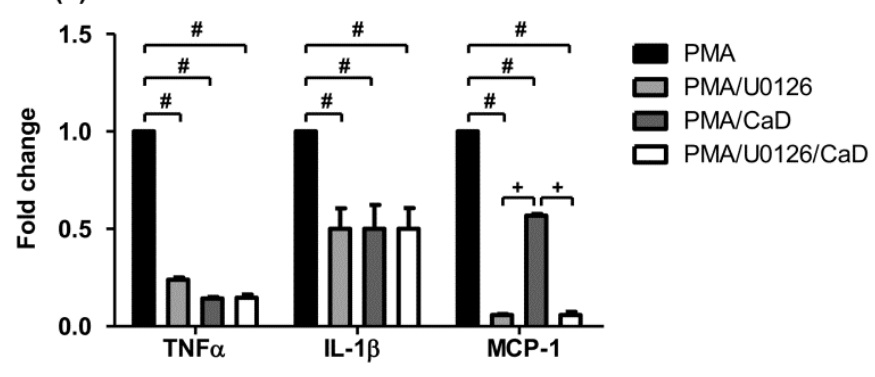

C (ii)

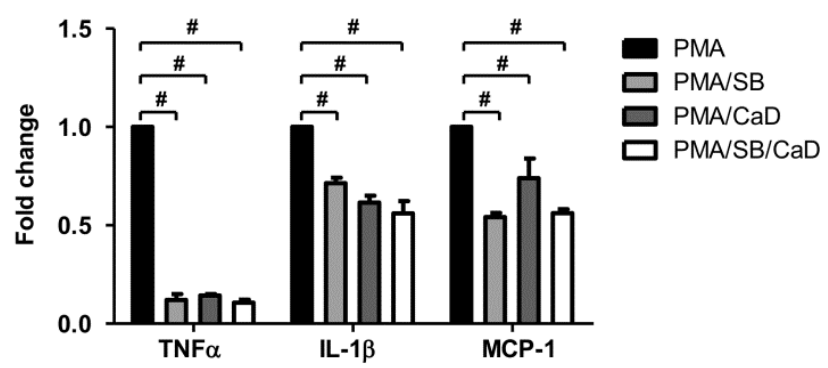

Figure 7. CaD suppresses the MAPK signaling to abolish monocyte-to-macrophage differentiation and inflammation. THP-1 monocytes were pretreated with an ERK1/2 (U0126) or P38 inhibitor (SB203580) for $1 \mathrm{~h}$, followed by CaD for $1 \mathrm{~h}$, and then treated with PMA ( $30 \mathrm{nmol} / \mathrm{L})$ for $72 \mathrm{~h}$. The differentiation and inflammation markers expression were measured by Western blotting (A), MMP9 activity was measured by gelatin zymography, and transcript levels (B,C) were measured by quantitative RT-PCR. $\Delta$, fold-change, normalized to PMA only $\left(n=3\right.$, mean \pm SEM. ${ }^{+} p<0.05$ vs. inhibitor treatment, $\# p<0.05$ vs. PMA only, one-way ANOVA). The Western blots represent one from at least three independent experiments.

\subsection{NF-kB Is Involved in CaD-Mediated Inhibition of Monocyte-to-Macrophage Differentiation and Inflammation}

We attempted to clarify whether $\mathrm{CaD}$ inhibits NF-kB expression in PMA-induced monocyte-to-macrophage differentiation and inflammation because PKC regulates NF-kB acti- 
vation in macrophages [35]. Figure $8 \mathrm{~A}$ demonstrates that $\mathrm{CaD}$ inhibits I $\mathrm{K} \mathrm{B} \alpha$ phosphorylation during monocyte-to-macrophage differentiation; furthermore, $\mathrm{CaD}$ inhibited IкB $\alpha$ phosphorylation in THP-1 cells treated with LPS and high glucose (Supplementary Figure S4A,B).

A

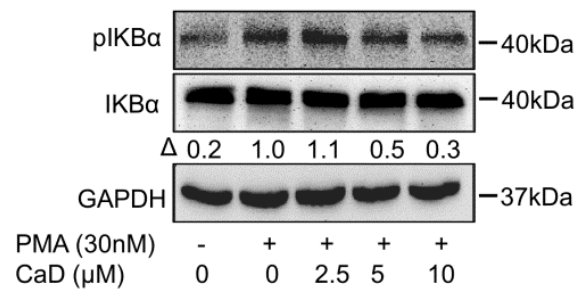

B

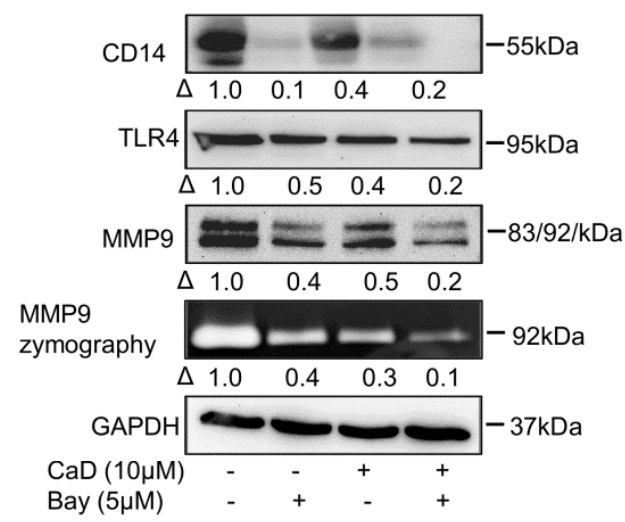

C(i)

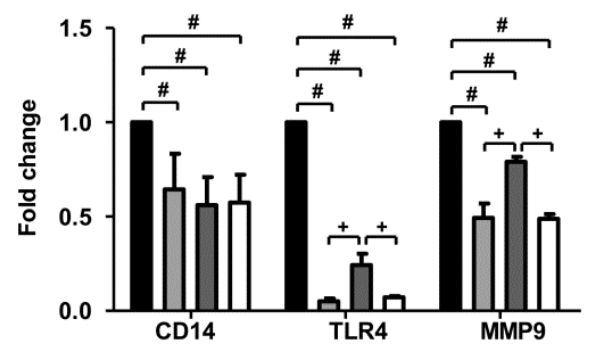

C(ii)

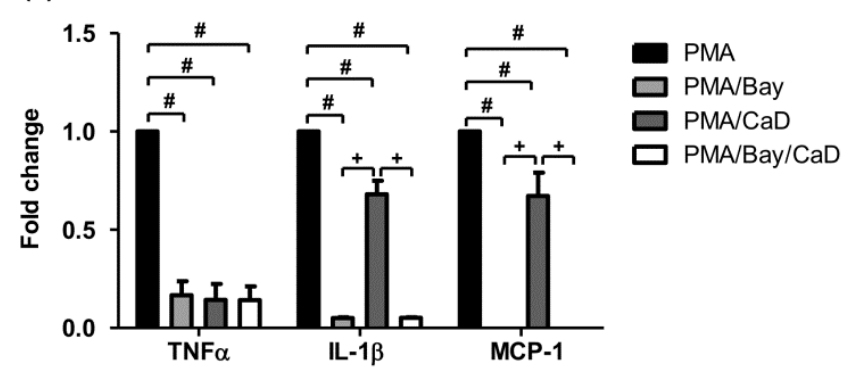

Figure 8. CaD inhibits monocyte-to-macrophage differentiation and inflammation in an NF-kB-dependent manner. THP-1 monocytes were pretreated with various concentrations $(0-10 \mu \mathrm{mol} / \mathrm{L})$ of $\mathrm{CaD}$ for $1 \mathrm{~h}$, followed by PMA treatment for $10 \mathrm{~min}$ (A). THP-1 monocytes were pretreated with an NF-kB inhibitor (Bay 11-7085) for $1 \mathrm{~h}$, followed by CaD for $1 \mathrm{~h}$, and then treated with PMA (30 nmol/L) for $72 \mathrm{~h}(\mathrm{~B}, \mathrm{C})$. IKB $\alpha$ phosphorylation and the differentiation and inflammation marker expression (A,B) were measured by Western blotting, MMP9 activity was measured by gelatin zymography, and transcript (C) levels were measured by quantitative RT-PCR. $\Delta$, fold change normalized to PMA only $(n=3$, mean \pm SEM. ${ }^{+} p<0.05$ vs. Bay treatment, ${ }^{\#} p<0.05$ vs. PMA only, one-way ANOVA). The Western blots represent one from at least three independent experiments.

By using an NF-kB inhibitor (Bay-117085), we showed that similar to CaD treatment, Bay-117085 attenuated PMA-induced expression of differentiation and inflammation markers (Figure 8B,C). These results tie well with previous studies where CaD suppressed NF- $\kappa$ B activation [11] and I $\kappa B-\alpha$ phosphorylation [42] in in vivo and in vitro diabetic models, subsequently inhibiting inflammation.

\subsection{Effect of $\mathrm{CaD}$ on NADPH Oxidase Activation}

NADPH oxidase is critical for ROS generation in phagocytic cells, and ROS are implicated in various cell signaling processes, including monocyte-to-macrophage differentiation [43]. We next investigated the effect of CaD on PMA-triggered ROS generation, NOX-2/p47phox activation, and p47phox membrane translocation. We used $\mathrm{N}$-acetylcysteine (NAC) as a ROS scavenger control to investigate its effect on p47phox activation and membrane translocation. Figure 9(Ai) shows that although ROS production increased with time, CaD quenched PMA-induced ROS production time independently; moreover, CaD blocked ROS generation dose-dependently. Both CaD and NAC inhibited PMA-triggered NOX2/p47phox expression and membrane translocation (Figure 9B,C). 
A (i)

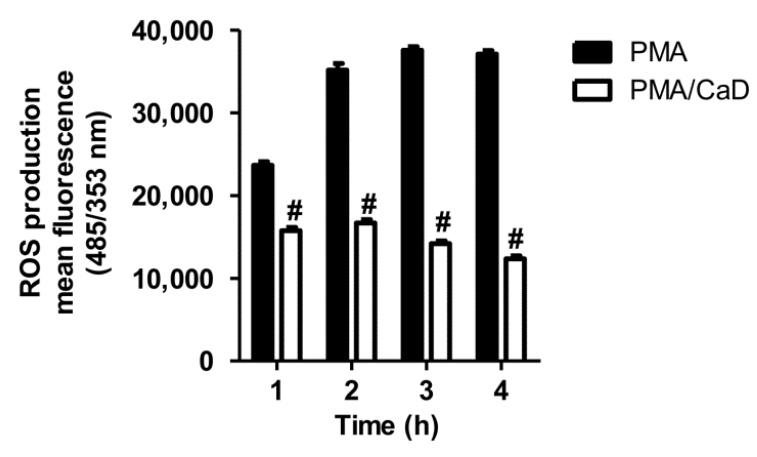

B (i)

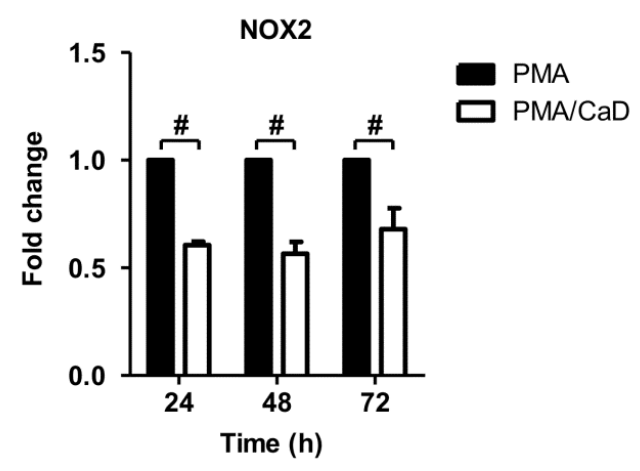

C (i)

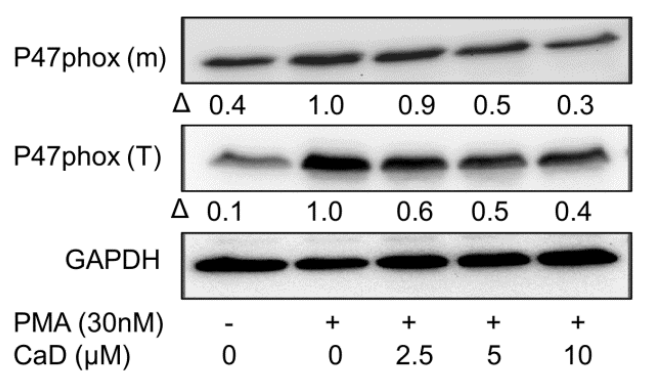

A (ii)

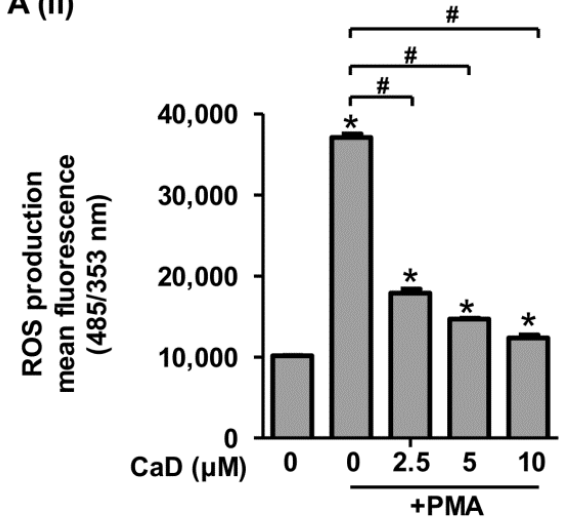

B (ii)

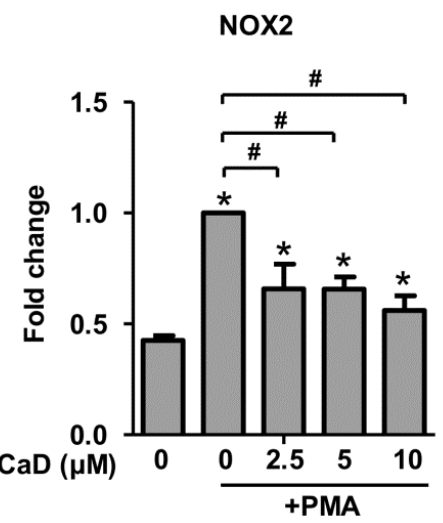

C (ii)

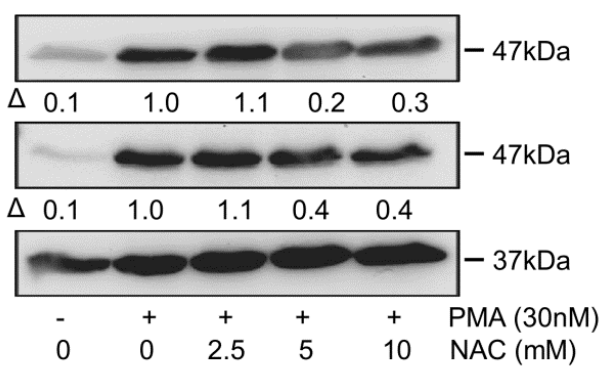

Figure 9. $\mathrm{CaD}$ modulates the ROS-NADPH oxidase pathway during monocyte-to-macrophage differentiation and inflammation. THP-1 monocytes were pretreated with $\mathrm{CaD}(10 \mu \mathrm{mol} / \mathrm{L})$, or various concentrations $(0-10 \mu \mathrm{mol} / \mathrm{L})$ of $\mathrm{CaD} / \mathrm{N}$-acetylcysteine (NAC) for $1 \mathrm{~h}$, followed by PMA $(30 \mathrm{nmol} / \mathrm{L})$ treatment for various time points $(\mathbf{A i}, \mathbf{B i})$, for $4 \mathrm{~h}$ (Aii), or $24 \mathrm{~h}$ (Bii,C). ROS production (A) was measured using the cell-permeable indicator $\mathrm{H}_{2}$ DCF-DA as described in the Materials and Methods section. NOX2 transcript levels (B) were measured by quantitative RT-PCR, and total p47phox protein expression $(\mathrm{T})$ and membrane translocation $(\mathrm{m})(\mathrm{C})$ were measured by Western blotting. $\Delta$, fold-change normalized to PMA only $\left(n=3\right.$, mean \pm SEM. ${ }^{*} p<0.05$ vs. no treatment, ${ }^{\#} p<0.05$ vs. PMA only, Student's $t$-test (Ai,Bi), or one-way ANOVA (Aii,Bii). The Western blots represent one from at least three independent experiments.

ROS regulate LPS and glucose-mediated NF-kB activation and inflammatory marker expression in human monocytes/macrophages [38,44]. Therefore, we investigated the effects of CaD on LPS and high glucose-induced p47phox activation and membrane translocation. Supplementary Figure S4A,B indicates that CaD significantly inhibited LPS and glucose-induced p47phox activation and membrane translocation. We further validated the role of ROS, NADPH oxidase, and the effect of CaD during monocyte-to-macrophage 
differentiation and inflammation in THP-1 cells by inhibiting NADPH oxidase (NOX2, p47phox) with a NADPH oxidase inhibitor (diphenyleneiodonium chloride, DPI), or NAC, in the presence or absence of CaD. DPI suppressed CD14, TLR4, MMP9, TNF $\alpha, \operatorname{IL} 1 \beta$, and MCP-1 expression (Figure 10), and NAC suppressed CD14, TLR4, and MMP9 expression (Supplementary Figure S5A) (we did not investigate the effect of NAC on pro-inflammatory cytokines as this question has been widely discussed).
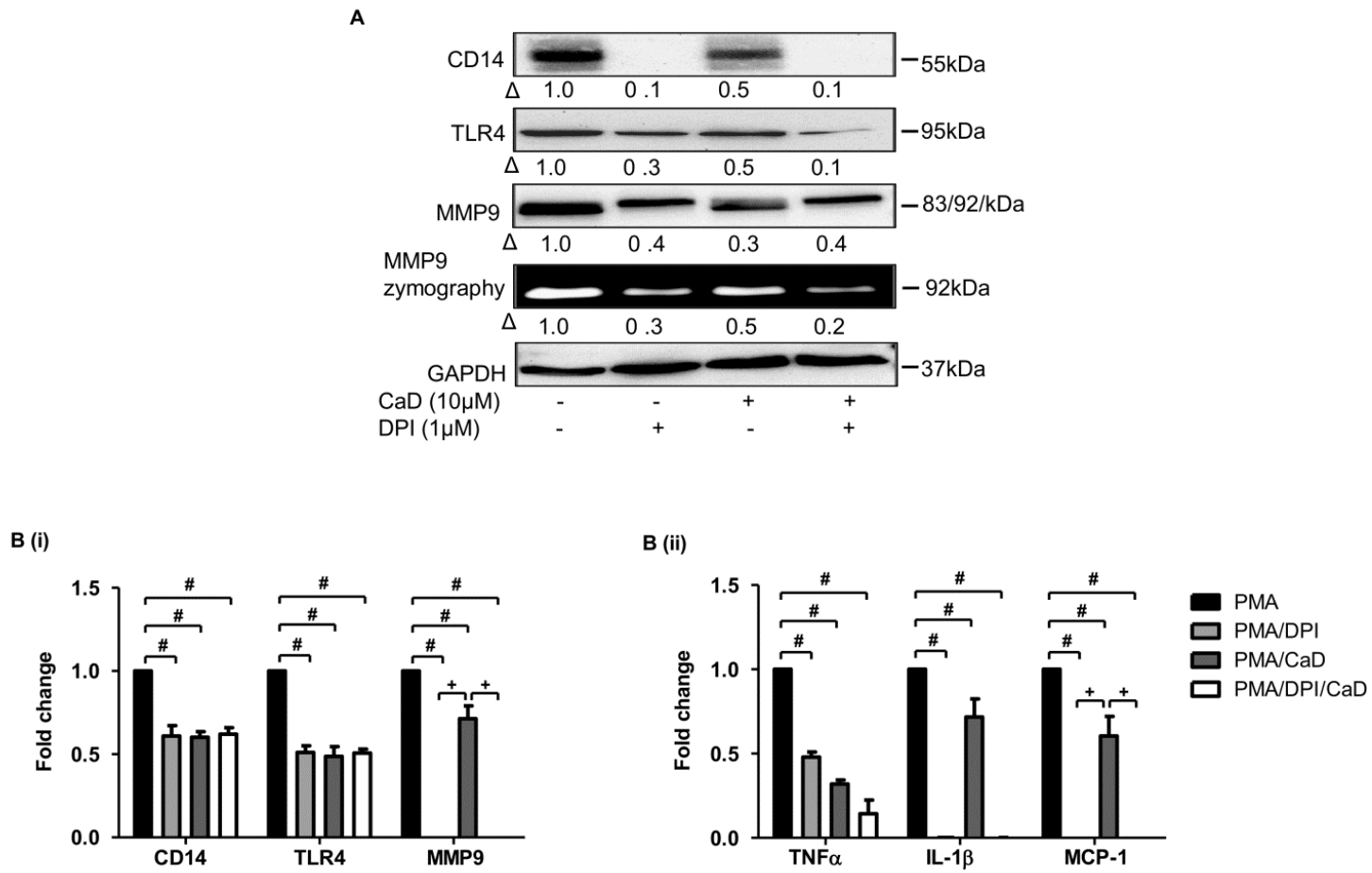

Figure 10. A NOX2 inhibitor (DPI) abrogates PMA-induced monocyte-to-macrophage differentiation and inflammation. THP-1 monocytes were pretreated with DPI for $1 \mathrm{~h}$, followed by CaD for $1 \mathrm{~h}$, and then treated with PMA (30 nmol/L) for $72 \mathrm{~h}$. Differentiation and inflammation marker expression was measured by Western blotting (A), MMP9 activity was measured by gelatin zymography, and transcript (B) levels (B) were measured by quantitative RT-PCR. $\Delta$, fold-change normalized to PMA only. $\left(n=3\right.$, mean \pm SEM. ${ }^{+} p<0.05$ vs. DPI treatment, ${ }^{*} p<0.05$ vs. PMA only, one-way ANOVA). The Western blots represent one from at least three independent experiments.

\subsection{Proximal Signaling Mediator under CaD Treatment}

After identifying signaling pathways inhibited by $\mathrm{CaD}$, we used the PMA-THP-1 cell model to determine a proximal signaling mediator via the use of specific pharmacological inhibitors.

First, because PKC $\delta$ is upstream to p47phox, p38, ERK1/2, and NF-KB [45,46], we examined the effect of PKC $\delta$ on p47phox activation and membrane translocation, and ERK1/2, P38, and IKB $\alpha$ phosphorylation. PKC $\delta$ inhibitor (rottlerin) significantly decreased p47phox activation $(\mathrm{T})$ and membrane $(\mathrm{m})$ translocation. Rottlerin also decreased ERK1/2, P38, and IKB $\alpha$ phosphorylation in a manner comparable to CaD treatment (Supplementary Figure S6). The findings indicated that NOX2/p47phox, MAPK, and NF$\mathrm{KB}$ are downstream targets of $\mathrm{PKC} \delta$ and that $\mathrm{CaD}$ inhibits their activation by modulating $\mathrm{PKC} \delta$.

Second, we treated cells with ERK1/2, p38, and NOX2/p47phox inhibitors and challenged these with PMA in the presence or absence of $\mathrm{CaD}$. PKC $\delta$ expression and activation did not change with p38, ERK1/2, or NOX2/p47phox inhibitors (data not shown); thus, we confirmed the above findings that MAPK and NOX2/p47phox are downstream of PKC $\delta$. 


\subsection{CaD Inhibits PKC $\delta$ via Its Antioxidant Activity}

Next, we asked how $\mathrm{CaD}$ regulates PKC $\delta$ during monocyte-to-macrophage differentiation. It is known that PMA activates, subsequently degrades, and depletes phorbol ester-responsive PKC isoforms, such as PKC $\delta$ [47], either via the ubiquitin-proteasome system [48] or $\mathrm{Ca}^{+}$-activated neutral proteases, such as calpains [49]. By using MG132 (proteasome inhibitor) and ALLM (calpain inhibitor), we ruled out CaD downregulation of PKC $\delta$ via proteasome and calpain mechanisms (data not shown).

ROS is not only a downstream but also an upstream signaling molecule to PKC $[38,44]$. Because of our findings that $\mathrm{CaD}$ suppressed PKC $\delta$ activation, we hypothesized that $\mathrm{CaD}$ downregulates PKC $\delta$ by inhibiting ROS activity. Indeed NAC significantly inhibited PMAinduced PKC $\delta$ activation and expression (Supplementary Figure S5B), indicating that ROS acts upstream of PKC $\delta$.

Because $\mathrm{H}_{2} \mathrm{O}_{2}$ activates PKC $\delta$ [50] and induces oxidative stress [51], we further investigated the effect of $\mathrm{CaD}$ on $\mathrm{H}_{2} \mathrm{O}_{2}$-induced $\mathrm{PKC} \delta$ activation. As expected, $\mathrm{H}_{2} \mathrm{O}_{2}$ activated PKC $\delta$ as early as $5 \mathrm{~min}$, and $\mathrm{PKC} \delta$ phosphorylation was depleted by $30 \mathrm{~min}$ in $\mathrm{H}_{2} \mathrm{O}_{2-}$ treated THP-1 cells (Figure 11A). CaD treatment significantly abolished the effect of $\mathrm{H}_{2} \mathrm{O}_{2}$ on PKC $\delta$ and p47phox activation (Figure 11A,B). These data showed that $\mathrm{CaD}$ is a ROS scavenger that downregulates PKC $\delta$ signaling.

\section{A}
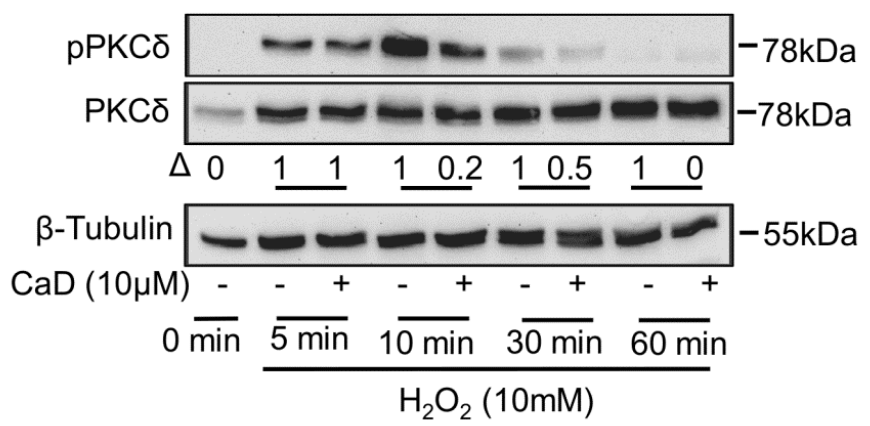

B

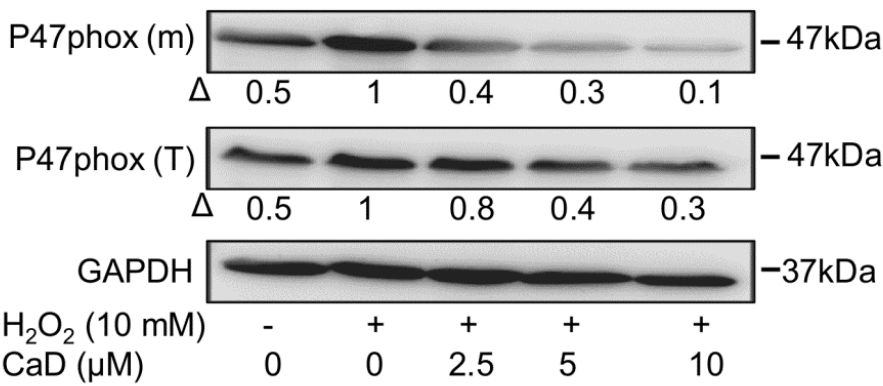

Figure 11. Effect of $\mathrm{CaD}$ on $\mathrm{H}_{2} \mathrm{O}_{2}$-activated PKC $\delta$ and NADPH oxidase. THP-1 monocytes were pretreated with various $\mathrm{CaD}$ concentrations for $1 \mathrm{~h}$, followed by $\mathrm{H}_{2} \mathrm{O}_{2}(10 \mathrm{mmol} / \mathrm{L})$ for different time points (A) or $24 \mathrm{~h}(\mathbf{B})$. Phosphorylation of $\mathrm{PKC} \delta$, and activation and membrane translocation of p47phox were measured by Western blotting. $\Delta$, fold-change normalized to $\mathrm{H}_{2} \mathrm{O}_{2}$ only. One representative image of at least three independent experiments is depicted.

\section{Discussion}

Calcium dobesilate $(\mathrm{CaD})$ is a synthetic agent that is vasoprotective via its ability to reduce capillary permeability. Specifically, $\mathrm{CaD}$ is known to reduce diabetic microvascular complications, reduce oxidative stress, and inhibit inflammation. However, its mechanism(s) in mediating these events has remained unknown. Consequently, we hypothesized that $\mathrm{CaD}$ might reduce monocyte-to-macrophage differentiation, one specific hallmark of 
inflammation (and atherosclerosis) that involves signaling via PKC $\delta$ and MAPK, previously shown as mediators of $\mathrm{CaD}$ activity in a diabetes model [14,37].

To assess this hypothesis, we used three specific models for monocyte-to-macrophage differentiation: THP-1 leukemic monocyte treatment with (1) the phorbol ester PMA; (2) the bacterial endotoxin lipopolysaccharide (LPS); and (3) high-glucose treatment. Overall, we showed for the first time that $\mathrm{CaD}$ effectively affects such differentiation, as evidenced by downregulation of CD14, TLR4, and MMP9 [52]. Moreover, CaD produced consistent results in primary human macrophages. More specifically, we found that $\mathrm{CaD}$ inhibited CD14, TLR4, and MMP9 expression via a PKC 8 /NADPH oxidase/ROS/MAPK/NFKB-dependent pathway in PMA-treated THP-1 cells. Attenuation of this signaling cascade reduced both monocyte-to-macrophage differentiation and inflammation.

CD14 and TLR4 facilitate detection of LPS, while CD14 and TLR4 knockout mouse macrophages have impaired NF- $\mathrm{KB}$ pathway activation, resulting in deficient production of the pro-inflammatory cytokines IL6 and TNF $\alpha$ production, following LPS induction [29-31]. Moreover, CD14 and TLR4 play a vital role in initiating sterile inflammation related to atherosclerosis $[2,3,28]$. Therefore, the effect of $\mathrm{CaD}$ to decrease CD14 and TLR4 expression could offer one mechanism to explain why CaD inhibits NF- $\mathrm{KB}$ and suppresses the release of downstream NF- $\mathrm{KB}$ activation products-TNF $\alpha$, IL-1 $\beta$, IL-6, and MCP-1 in animal models of sepsis and diabetic nephropathy and retinopathy $[11,13,14,32]$. Indeed, in this study, $\mathrm{CaD}$ demonstrated potent anti-inflammatory effects by suppressing TNF $\alpha, \mathrm{IL}-1 \beta$, and MCP-1 levels in PMA, LPS, and high glucose-treated THP-1 cells, which CaD significantly suppressed, suggesting a broad therapeutic spectrum potential of $\mathrm{CaD}[11-14,32,53]$.

Once we established that $\mathrm{CaD}$ downregulated CD14 and TLR4 expression, we differentiated THP-1 cells and primary human monocytes to macrophages in the presence of $\mathrm{CaD}$ and investigated their response to LPS. As expected, CaD significantly inhibited LPS-induced pro-inflammatory cytokines expression and production in both types of macrophages. These results support a novel anti-inflammatory mechanism of CaD: inferring that $\mathrm{CaD}$ inhibits inflammation by suppressing macrophage CD14-TLR4 expression.

It is known that macrophages resident in human and experimental atherosclerosis colocalize with and release active matrix metalloproteinases (MMPs), including the gelatinase MMP9, which specializes in the digestion of basement membranes. Specifically, MMP9 is implicated in the pathogenesis of atherosclerosis [54], as its ablation protects apolipoprotein E-deficient mice against atherosclerosis [55]. Our observation that $\mathrm{CaD}$ significantly reduced MMP9 expression and activity corroborates a recent study in a rabbit model of atherosclerosis, in which $\mathrm{CaD}$ reduced MMP9 in local vascular walls reducing atherosclerotic plaque formation and improved endothelial function [56]. Given the importance of inflammation, macrophage activation, and MMP9 activity in atherosclerosis pathogenesis, our data suggest a promising potential of $\mathrm{CaD}$ as an anti-atherosclerotic agent.

To elucidate molecular mechanisms of how $\mathrm{CaD}$ impairs monocyte-to-macrophage differentiation and inflammation, we used a THP-1 leukemic monocyte cell model. PMA stimulates PKC-MAPK-NF- $\kappa B$ by acting as an analog of diacylglycerol, among the PKC isoforms, $P K C \alpha,-\beta$, and $-\delta$ play significant roles during monocyte-to-macrophage differentiation $[57,58]$. In addition to PMA, LPS and high glucose activate PKC $\delta$-MAPKNF- $\mathrm{kB}$ signaling [35-38]. The NF- $\mathrm{kB}$ pathway, in particular, is activated downstream of MEK/ERK $[59,60]$ and, in turn, plays a crucial role in activating inflammatory response genes. As expected, we observed that PMA, LPS, and high glucose activated PKC $\beta I$, PKC 8 , and MAPK (ERK1/2, P38, and JNK); PMA stimulated PKC $\alpha$ expression, albeit at a low level, most likely because PKC $\alpha$ is lowly expressed in THP-1 cells [27]. Although CaD treatment did not affect PKC $\alpha$, PKC $\beta$ II, and JNK, it significantly blunted PKC $\delta$, ERK1/2, and P38 activation. CaD, like other antioxidants, selectively inhibited PKC $\delta$-ERK1/2-P38dependent signaling during PMA-induced monocyte-to-macrophage differentiation [61,62]. These results correspond with previous studies in experimental diabetes where CaD inhibited PKC $\delta$, ERK1/2, and p38 activation [11,37]. Moreover, similar to previous studies, CaD inhibited PMA-, LPS-, and high glucose-induced NF-кB activation [11,32,42]. 
Our data showed that PKC $\delta, \mathrm{MAPK}$, and NF- $\mathrm{BB}$ inhibitors significantly decreased CD14, TLR4, MMP9, and pro-inflammatory cytokines expression. It is known that knocking down PKC $\delta$ in THP-1 cells significantly decreased PMA-induced CD14 expression [46]. PKC $\delta$ plays a role in TLR4 expression, TLR4-mediated cytokine secretion $[24,35,63]$, and MMP9 expression and activity [64]. Inhibiting or downregulating PKC $\delta$ in innate immunity cells decreases NF- $\mathrm{KB}$ activation and pro-inflammatory cytokines secretion [35]; inhibiting MAPK downregulates CD14, TLR4, MMP9, and pro-inflammatory markers expression [39-41]. Consistent with these studies, we showed that PKC $\delta, M A P K$, and NF- $\mathrm{B}$ inhibitors significantly downregulated CD14, TLR4, MMP9, and various pro-inflammatory cytokines. Therefore, through inactivating PKC $\delta, \mathrm{MAPK}$, and NF- $\mathrm{B}, \mathrm{CaD}$ indirectly decreased CD14, TLR4, and MMP-9 levels, inhibiting monocyte-to-macrophage differentiation and subsequent inflammation.

In addition, a PKC $\delta$ inhibitor suppressed ERK1/2, P38, and IKB- $\alpha$ phosphorylation to levels similar to $\mathrm{CaD}$ treatment, supporting previous findings that $\mathrm{PKC} \delta$ is the important PKC isoform upstream of ERK1/2, P38, and NF- $\mathrm{KB}$ activation in PMA-induced THP-1 cell differentiation [46]. From these results, it is clear that PKC $\delta$ mediated the effect of CaD during monocyte-to-macrophage differentiation and inflammation via inhibiting MAPK and NF- $\mathrm{KB}$ activation.

As oxidative stress is well established as associated with inflammation, we examined CaD effects on ROS. Specifically, NADPH oxidase is accepted as the most important inducer of phagocytic cell generation of ROS (especially $\mathrm{H}_{2} \mathrm{O}_{2}$ ), which acts as a second messenger in activating signaling pathways that induce monocyte adhesion, invasion, and migration in atherosclerosis [65]. ROS is also implicated in various cell signaling processes, including monocyte-to-macrophage differentiation [43], via glucose or PMA activation of PKC/MAPK signaling [66]; this is suppressed by antioxidants, such as curcumin, NAC, vitamin E, and vitamin C $[39,67]$. Additionally, $\mathrm{CaD}$ is a potent antioxidant in both in vitro and in vivo animal models $[11,12,68,69]$, although its exact mechanism is not fully elucidated. In the present study, we found that the ROS scavenger NAC and the NADPH oxidase inhibitor DPI inhibited CD14, TLR4, and MMP-9 expression in PMA-treated cells, while also demonstrating that $\mathrm{CaD}$ markedly suppressed ROS production during PMAinduced THP-1 differentiation. This is the first report of ROS modulating CD14 expression in human macrophages to the best of our knowledge. Recently, Akhter et al. reported that treatment of peripheral blood mononuclear cells with $\mathrm{H}_{2} \mathrm{O}_{2}$ induced TLR4 expression via ROS production [51], which also upregulates macrophage MMP-9 expression and cell migration [70]. These findings clearly show that $\mathrm{CaD}$ modulated monocyte-to-macrophage differentiation and inflammation via ROS scavenging.

The severity of atherosclerosis is well associated with NOX2 upregulation, which increases intracellular oxidative stress in macrophages [65]. Additionally, upregulated NOX2 correlates with plaque macrophage content in human coronary atherosclerosis [71]. In various disease models, PMA, LPS, and high glucose are known to activate NADPH oxidase assembly by promoting the phosphorylation and translocation of cytosolic p47phox [72-75]. This study demonstrated a novel antioxidant mechanism in which $\mathrm{CaD}$ downregulates NOX2 expression while also attenuating p47phox membrane translocation during THP-1 stimulation with PMA, LPS, and high glucose. Overall, these findings agree well with previous studies where antioxidants inhibited monocyte-to-macrophage differentiation and associated inflammation $[73,76]$. These results showed that CaD could block PMA, LPS, and glucose-induced ROS generation through the inhibition of p47phox/NOX2 activation. Thus, $\mathrm{CaD}$ could potentially provide a novel therapeutic approach targeting NOX2/p47phox-mediated complications, such as atherosclerosis [77], sepsis [78], and diabetic nephropathy [79].

Since PKC $\delta$ regulates $\mathrm{p} 47$ phox activation and translocation (thus contributing to monocyte NADPH oxidase activity [80]), we found both events to be significantly inhibited by rottlerin, in line with a previous study [80]. This suggests that NOX2/p47phox is a 
downstream target of PKC $\delta$, indicating a mechanism for NOX2/p47phox signal inhibition by $\mathrm{CaD}$.

Our findings that $\mathrm{CaD}$ regulated PKC $\delta$ activation and no known $\mathrm{CaD}-\mathrm{PKC} \delta$ interactions prompted us to investigate how $\mathrm{CaD}$ regulates $\mathrm{PKC} \delta$ during monocyte-tomacrophage differentiation. During oxidative stress, ROS can act both downstream and upstream of PKC. For example, ROS provides signal amplification during PMA-, LPS-, and high glucose-induced monocyte-to-macrophage differentiation or activation. This establishes a positive feedback loop to sustain ROS-PKC $\delta$ signaling [38,44], as ROS is also an upstream regulator of $\mathrm{PKC}$, under high glucose, in human peritoneal mesothelial cells [81] and antioxidants suppressed PKC activity in phorbol ester-stimulated human hepatoma cells [82]. Consistent with a previous report [83], the ROS scavenger NAC significantly inhibited $\mathrm{PKC} \delta$ activation and expression, likewise indicating that ROS act upstream of $\mathrm{PKC} \delta$.

Indeed, $\mathrm{H}_{2} \mathrm{O}_{2}$ treatment activated $\mathrm{PKC} \delta$ phosphorylation and p47phox activation, which was abrogated considerably by $\mathrm{CaD}$ treatment, proving $\mathrm{CaD}$ to be a ROS scavenger that downregulates PKC $\delta$ signaling. Our data clearly showed that during monocyteto-macrophage differentiation and inflammation, $\mathrm{CaD}$ inhibits PKC $\delta, \mathrm{NADPH}$ oxidase, ROS, MAPK, and NF- $\mathrm{kB}$ activation, decreasing the expression of CD14, TLR4, MMP9, and pro-inflammatory cytokines. Several studies support the hypothesis that a PKC isoform inhibitor (such as PKC $\delta$ inhibitor) might prevent or decrease hyperglycemiainduced atherosclerosis [84]. Therefore, our results further suggest that $\mathrm{CaD}^{\prime} \mathrm{s}$ ability to suppress PKC $\delta$ activation may likewise provide advantages in modulating the process of atherosclerosis.

One limitation of this study is that we cannot rule out that $\mathrm{CaD}$ downregulates the PKC $\delta$ pathway via VEGF signaling since $\mathrm{CaD}$ is also a VEGF signaling inhibitor in endothelial cells [14]. ROS scavengers can also inhibit angiogenic factor production due to a direct effect on monocytes/macrophages [85], and antioxidants, such as phenolic compounds, vitamins $C$ and $E$, likewise inhibit VEGF-VEGFR signaling [86,87]. Accordingly, in this study, we detected a significant decrease in VEGF expression in THP-1 cells treated with PMA in the presence of $\mathrm{CaD}$ (Supplementary Figure S7). Nonetheless, this is an exciting topic for future research.

In summary, we (1) demonstrated for the first time that $\mathrm{CaD}$ effectively downregulates CD14, TLR4, MMP9, IL1 $\beta$, TNF $\alpha$, and MCP-1 expression during THP-1 macrophage differentiation and translated our findings to primary human macrophages; (2) provided evidence that $\mathrm{CaD}$ inhibits PKC $\delta$-dependent NADPH oxidase-MAPK-and NF- $\mathrm{KB}$ signaling, and (3) illustrated that $\mathrm{CaD}$ downregulates PKC $\delta$ activation by inhibiting ROS-driven oxidative stress.

\section{Conclusions}

The present study identified a novel mechanism of how $\mathrm{CaD}$ alleviates metabolic and infectious inflammation, including suppressed oxidative stress-dependent CD14/TLR4 expression and the associated inflammation. The results suggest that $\mathrm{CaD}$ can prevent or treat inflammatory conditions related to inflammatory macrophages. Future research should further develop and confirm these findings in in vivo models.

Supplementary Materials: The following are available online at https: / www.mdpi.com/article / 10.3390/antiox10111798/s1, Figure S1: Effect of calcium dobesilate (CaD) onTHP-1 cells viability and adhesion, Figure S2: Effect of calcium dobesilate (CaD) on LPS stimulated THP-1 monocytes, Figure S3: Effect of calcium dobesilate $(\mathrm{caD})$ on high glucose-induced inflammation, Figure S4: The effect of calcium dobesilate (CaD) on signaling pathways induced by high glucose and LPS, Figure S5: N-acetylcysteine (NAC) inhibits monocyte-to-macrophage differentiation and inflammation, Figure S6: PKC $\delta$ is the proximal target of calcium dobesilate (CaD), Figure S7: Calcium dobesilate $(\mathrm{CaD})$ downregulates VEGF expression. 
Author Contributions: Conceptualization, methodology, investigation, writing-original draft preparation F.N.; resources, writing-review and editing, supervision, funding acquisition, H.H. All authors have read and agreed to the published version of the manuscript.

Funding: This research was funded by Deutsche Forschungsgemeinschaft [HA: 1388/18-1]; and Else Kröner-Fresenius Foundation [HA: 2017_A96].

Institutional Review Board Statement: Not applicable.

Informed Consent Statement: Not applicable.

Data Availability Statement: All the data presented in this study are included in the article and its Supplementary Material.

Acknowledgments: We thank Frank Hausadel, Petra Wübbolt-Lehmann, and Birgit Habermeir for excellent technical assistance.

Conflicts of Interest: The authors declare no conflict of interest.

\section{References}

1. Park, Y.M. CD36, a scavenger receptor implicated in atherosclerosis. Exp. Mol. Med. 2014, 46, e99. [CrossRef] [PubMed]

2. Hermansson, C.; Lundqvist, A.; Magnusson, L.U.; Ullström, C.; Bergström, G.; Hultén, L.M. Macrophage CD14 expression in human carotid plaques is associated with complicated lesions, correlates with thrombosis, and is reduced by angiotensin receptor blocker treatment. Int. Immunopharmacol. 2014, 22, 318-323. [CrossRef] [PubMed]

3. Li, B.; Xia, Y.; Hu, B. Infection and atherosclerosis: TLR-dependent pathways. Cell. Mol. Life Sci. 2020, 77, 2751-2769. [CrossRef] [PubMed]

4. Xing, S.; Zheng, F.; Zhang, W.; Wang, D.; Xing, Q. Relationship between toll-like receptor 4 levels in aorta and severity of atherosclerosis. J. Int. Med. Res. 2014, 42, 958-965. [CrossRef]

5. Xu, Q.; Choksi, S.; Qu, J.; Jang, J.; Choe, M.; Banfi, B.; Engelhardt, J.; Liu, Z.-G. NADPH Oxidases Are Essential for Macrophage Differentiation. J. Biol. Chem. 2016, 291, 20030-20041. [CrossRef]

6. Moss, J.W.; Ramji, D.P. Cytokines: Roles in atherosclerosis disease progression and potential therapeutic targets. Future Med. Chem. 2016, 8, 1317-1330. [CrossRef]

7. Dollery, C.M.; Libby, P. Atherosclerosis and proteinase activation. Cardiovasc. Res. 2006, 69, 625-635. [CrossRef]

8. Ezhov, M.; Safarova, M.; Afanasieva, O.; Mitroshkin, M.; Matchin, Y.; Pokrovsky, S. Matrix Metalloproteinase 9 as a Predictor of Coronary Atherosclerotic Plaque Instability in Stable Coronary Heart Disease Patients with Elevated Lipoprotein(a) Levels. Biomolecules 2019, 9, 129. [CrossRef]

9. Quesada, I.; Lucero, A.; Amaya, C.; Meijles, D.; Cifuentes, M.; Pagano, P.; Castro, C. Selective inactivation of NADPH oxidase 2 causes regression of vascularization and the size and stability of atherosclerotic plaques. Atherosclerosis 2015, 242, 469-475. [CrossRef]

10. Cannizzo, B.; Quesada, I.; Militello, R.; Amaya, C.; Miatello, R.; Cruzado, M.; Castro, C. Tempol attenuates atherosclerosis associated with metabolic syndrome via decreased vascular inflammation and NADPH-2 oxidase expression. Free Radic. Res. 2014, 48, 526-533. [CrossRef]

11. Leal, E.C.; Martins, J.; Voabil, P.; Liberal, J.; Chiavaroli, C.; Bauer, J.; Cunha-Vaz, J.; Ambrósio, A.F. Calcium Dobesilate Inhibits the Alterations in Tight Junction Proteins and Leukocyte Adhesion to Retinal Endothelial Cells Induced by Diabetes. Diabetes 2010, 59, 2637-2645. [CrossRef] [PubMed]

12. Voabil, P.; Liberal, J.; Leal, E.C.; Bauer, J.; Cunha-Vaz, J.; Santiago, A.R.; Ambrósio, A.F. Calcium Dobesilate Is Protective against Inflammation and Oxidative/Nitrosative Stress in the Retina of a Type 1 Diabetic Rat Model. Ophthalmic Res. 2017, 58, 150-161. [CrossRef] [PubMed]

13. Bogdanov, P.; Solà-Adell, C.; Hernández, C.; García-Ramírez, M.; Sampedro, J.; Simó-Servat, O.; Valeri, M.; Pasquali, C.; Simó, R. Calcium dobesilate prevents the oxidative stress and inflammation induced by diabetes in the retina of $\mathrm{db} / \mathrm{db}$ mice. J. Diabetes Its Complicat. 2017, 31, 1481-1490. [CrossRef]

14. Njau, F.; Shushakova, N.; Schenk, H.; Wulfmeyer, V.C.; Bollin, R.; Menne, J.; Haller, H. Calcium dobesilate reduces VEGF signaling by interfering with heparan sulfate binding site and protects from vascular complications in diabetic mice. PLoS ONE 2020, 15, e0218494. [CrossRef]

15. Graber, R.; Farine, J.-C.; Losa, G.A. Calcium Dobesilate protects human peripheral blood mononuclear cells from oxidation and apoptosis. Apoptosis 1998, 3, 41-49. [CrossRef] [PubMed]

16. Piller, N.B. Assessment of the anti-inflammatory action of calcium dobesilate. Effect on macrophages attaching to subcutaneously implanted coverslips in guinea pigs. Arzneimittelforschung 1990, 40, 698-700. [PubMed]

17. He, Z.; Chen, J.; Zhu, X.; An, S.; Dong, X.; Yu, J.; Zhang, S.; Wu, Y.; Li, G.; Zhang, Y.; et al. NLRP3 Inflammasome Activation Mediates Zika Virus-Associated Inflammation. J. Infect. Dis. 2018, 217, 1942-1951. [CrossRef]

18. Lee, S.-M.; Kim, E.-J.; Suk, K.; Lee, W.-H. Stimulation of FasL Induces Production of Proinflammatory Mediators Through Activation of Mitogen-Activated Protein Kinases and Nuclear Factor- $\kappa$ B in THP-1 Cells. Inflammation 2012, 35, 1-10. [CrossRef] 
19. Bai, X.; Feldman, N.E.; Chmura, K.; Ovrutsky, A.R.; Su, W.-L.; Griffin, L.; Pyeon, D.; McGibney, M.T.; Strand, M.; Numata, M.; et al. Inhibition of Nuclear Factor-Kappa B Activation Decreases Survival of Mycobacterium tuberculosis in Human Macrophages. PLOS ONE 2013, 8, e61925. [CrossRef]

20. Hattori, T.; Watanabe-Takahashi, M.; Ohoka, N.; Hamabata, T.; Furukawa, K.; Nishikawa, K.; Naito, M. Proteasome inhibitors prevent cell death and prolong survival of mice challenged by Shiga toxin. FEBS Open Biol. 2015, 5, 605-614. [CrossRef]

21. Zhao, Y.; Malinin, N.; Meller, J.; Ma, Y.; West, X.Z.; Bledzka, K.; Qin, J.; Podrez, E.A.; Byzova, T.V. Regulation of Cell Adhesion and Migration by Kindlin-3 Cleavage by Calpain. J. Biol. Chem. 2012, 287, 40012-40020. [CrossRef] [PubMed]

22. Park, S.Y.; Lee, S.W.; Kim, H.Y.; Lee, S.Y.; Lee, W.S.; Hong, K.W.; Kim, C.D. SIRT1 inhibits differentiation of monocytes to macrophages: Amelioration of synovial inflammation in rheumatoid arthritis. J. Mol. Med. 2016, 94, 921-931. [CrossRef] [PubMed]

23. Nakayama, M.; Niki, Y.; Kawasaki, T.; Takeda, Y.; Ikegami, H.; Toyama, Y.; Miyamoto, T. IL-32-PAR2 axis is an innate immunity sensor providing alternative signaling for LPS-TRIF axis. Sci. Rep. 2013, 3, 2960. [CrossRef] [PubMed]

24. Dasu, M.R.; Devaraj, S.; Zhao, L.; Hwang, D.H.; Jialal, I. High Glucose Induces Toll-Like Receptor Expression in Human Monocytes: Mechanism of Activation. Diabetes 2008, 57, 3090-3098. [CrossRef] [PubMed]

25. Sindhu, S.; Akhter, N.; Kochumon, S.; Thomas, R.; Wilson, A.; Shenouda, S.; Tuomilehto, J.; Ahmad, R. Increased Expression of the Innate Immune Receptor TLR10 in Obesity and Type-2 Diabetes: Association with ROS-Mediated Oxidative Stress. Cell. Physiol. Biochem. 2018, 45, 572-590. [CrossRef]

26. Toth, M.; Sohail, A.; Fridman, R. Assessment of Gelatinases (MMP-2 and MMP-9) by Gelatin Zymography. In Metastasis Research Protocols; Humana Press: Totowa, NJ, USA, 2012; pp. 163-174.

27. Schwende, H.; Fitzke, E.; Ambs, P.; Dieter, P. Differences in the state of differentiation of THP-1 cells induced by phorbol ester and 1,25-dihydroxyvitamin D3. J. Leukoc. Biol. 1996, 59, 555-561. [CrossRef]

28. Ding, Y.; Subramanian, S.; Montes, V.N.; Goodspeed, L.; Wang, S.; Han, C.; TeresaIII, A.S.; Kim, J.; O’Brien, K.D.; Chait, A. Toll-Like Receptor 4 Deficiency Decreases Atherosclerosis But Does Not Protect Against Inflammation in Obese Low-Density Lipoprotein Receptor-Deficient Mice. Arterioscler. Thromb. Vasc. Biol. 2012, 32, 1596-1604. [CrossRef]

29. Perera, P.Y.; Vogel, S.N.; Detore, G.R.; Haziot, A.; Goyert, S. CD14-dependent and CD14-independent signaling pathways in murine macrophages from normal and CD14 knockout mice stimulated with lipopolysaccharide or taxol. J. Immunol. 1997, $158,158$.

30. Takeuchi, O.; Hoshino, K.; Kawai, T.; Sanjo, H.; Takada, H.; Ogawa, T.; Takeda, K.; Akira, S. Differential Roles of TLR2 and TLR4 in Recognition of Gram-Negative and Gram-Positive Bacterial Cell Wall Components. Immunity 1999, 11, 443-451. [CrossRef]

31. Hoshino, K.; Takeuchi, O.; Kawai, T.; Sanjo, H.; Ogawa, T.; Takeda, Y.; Takeda, K.; Akira, S. Cutting edge: Toll-like receptor 4 (TLR4)-deficient mice are hyporesponsive to lipopolysaccharide: Evidence for TLR4 as the Lps gene product. J. Immunol. 1999, $162,3749-3752$.

32. Angulo, J.; Cuevas, P.; Cuevas, B.; El Youssef, M.; Fernández, A.; Martínez-Salamanca, E.; González-Corrochano, R.; GiménezGallego, G. Diacetyloxyl derivatization of the fibroblast growth factor inhibitor dobesilate enhances its anti-inflammatory, anti-angiogenic and anti-tumoral activities. J. Transl. Med. 2015, 13, 48. [CrossRef]

33. Li, L.; Yan, D.; Zou, Y.; Zhang, T.; Lin, G.; Xiao, J. A herbal extract treats type 2 diabetes mellitus effectively by down-regulating expression of CD14. Int. J. Clin. Exp. Med. 2019, 2, 1535-1544.

34. Richter, E.; Ventz, K.; Harms, M.; Mostertz, J.; Hochgräfe, F. Induction of Macrophage Function in Human THP-1 Cells Is Associated with Rewiring of MAPK Signaling and Activation of MAP3K7 (TAK1) Protein Kinase. Front. Cell Dev. Biol. $2016,4,21$. [CrossRef] [PubMed]

35. Kontny, E.; Kurowska, M.; Szczepańska, K.; Maśliński, W. Rottlerin, a PKC isozyme-selective inhibitor, affects signaling events and cytokine production in human monocytes. J. Leukoc. Biol. 2000, 67, 249-258. [CrossRef]

36. Noh, K.T.; Son, K.H.; Jung, I.D.; Kang, H.K.; Hwang, S.A.; Lee, W.S.; You, J.C.; Park, Y.-M. Protein Kinase C $\delta$ (PKC $\delta$ )-Extracellular Signal-regulated Kinase 1/2 (ERK1/2) Signaling Cascade Regulates Glycogen Synthase Kinase-3 (GSK-3) Inhibition-mediated Interleukin-10 (IL-10) Expression in Lipopolysaccharide (LPS)-induced Endotoxemia. J. Biol. Chem. 2012, 287, 14226-14233. [CrossRef] [PubMed]

37. Solà-Adell, C.; Bogdanov, P.; Hernández, C.; Sampedro, J.; Valeri, M.; Garcia-Ramírez, M.; Pasquali, C.; Simó, R. Calcium Dobesilate Prevents Neurodegeneration and Vascular Leakage in Experimental Diabetes. Curr. Eye Res. 2017, 42, 1273-1286. [CrossRef]

38. Dasu, M.R.; Devaraj, S.; Jialal, I. High glucose induces IL-1ß expression in human monocytes: Mechanistic insights. Am. J. Physiol. Endocrinol. Metab. 2007, 293, E337-E346. [CrossRef]

39. Cao, J.; Han, Z.; Tian, L.; Chen, K.; Fan, Y.; Ye, B.; Huang, W.; Wang, C.; Huang, Z. Curcumin inhibits EMMPRIN and MMP-9 expression through AMPK-MAPK and PKC signaling in PMA induced macrophages. J. Transl. Med. 2014, 12, 1-10. [CrossRef]

40. Peroval, M.Y.; Boyd, A.C.; Young, J.R.; Smith, A.L. A Critical Role for MAPK Signalling Pathways in the Transcriptional Regulation of Toll Like Receptors. PLoS ONE 2013, 8, e51243. [CrossRef]

41. Tong, W.; Chen, X.; Song, X.; Chen, Y.; Jia, R.; Zou, Y.; Li, L.; Yin, L.; He, C.; Liang, X.; et al. Resveratrol inhibits LPS-induced inflammation through suppressing the signaling cascades of TLR4-NF-kB/MAPKs/IRF3. Exp. Ther. Med. 2019, 19, 1824-1834. [CrossRef] 
42. Zhou, Y.; Qi, C.; Li, S.; Shao, X.; Ni, Z. Investigation of the Mechanism Underlying Calcium Dobesilate-Mediated Improvement of Endothelial Dysfunction and Inflammation Caused by High Glucose. Mediat. Inflamm. 2019, 2019, 9893682. [CrossRef] [PubMed]

43. Traore, K.; Trush, M.A.; George, M.; Spannhake, E.W.; Anderson, W.; Asseffa, A. Signal transduction of phorbol 12-myristate 13-acetate (PMA)-induced growth inhibition of human monocytic leukemia THP-1 cells is reactive oxygen dependent. Leuk. Res. 2005, 29, 863-879. [CrossRef] [PubMed]

44. Hsu, H.-Y.; Wen, M.-H. Lipopolysaccharide-mediated Reactive Oxygen Species and Signal Transduction in the Regulation of Interleukin-1 Gene Expression. J. Biol. Chem. 2002, 277, 22131-22139. [CrossRef]

45. Qiao, H.; May, J.M. Macrophage differentiation increases expression of the ascorbate transporter (SVCT2). Free Radic. Biol. Med. 2009, 46, 1221-1232. [CrossRef] [PubMed]

46. Tsai, C.-S.; Lin, Y.-W.; Huang, C.-Y.; Tsai, Y.-T.; Tsao, N.-W.; Lin, C.-S.; Jeng, H.; Lin, F.-Y.; Shih, C.-M.; Shih, C.-C. Thrombomodulin regulates monocye differentiation via PKC $\delta$ and ERK1/2 pathway in vitro and in atherosclerotic artery. Sci. Rep. 2016, 6, 38421. [CrossRef]

47. Newton, A.C. Protein kinase C as a tumor suppressor. Semin. Cancer Biol. 2018, 48, 18-26. [CrossRef] [PubMed]

48. Lu, Z.; Liu, D.; Hornia, A.; Devonish, W.; Pagano, M.; Foster, D.A. Activation of Protein Kinase C Triggers Its Ubiquitination and Degradation. Mol. Cell. Biol. 1998, 18, 839-845. [CrossRef]

49. Hong, D.-H.; Huan, J.; Ou, B.-R.; Yeh, J.-Y.; Saido, T.C.; Cheeke, P.; Forsberg, N.E. Protein kinase C isoforms in muscle cells and their regulation by phorbol ester and calpain. Biochim. Biophys. Acta Mol. Cell Res. 1995, 1267, 45-54. [CrossRef]

50. Konishi, H.; Yamauchi, E.; Taniguchi, H.; Yamamoto, T.; Matsuzaki, H.; Takemura, Y.; Ohmae, K.; Kikkawa, U.; Nishizuka, Y. Phosphorylation sites of protein kinase $\mathrm{C} \delta$ in $\mathrm{H}_{2} \mathrm{O}_{2}$-treated cells and its activation by tyrosine kinase in vitro. Proc. Natl. Acad. Sci. USA 2001, 98, 6587-6592. [CrossRef]

51. Akhter, N.; Madhoun, A.; Arefanian, H.; Wilson, A.; Kochumon, S.; Thomas, R.; Shenouda, S.; Al-Mulla, F.; Ahmad, R.; Sindhu, S. Oxidative Stress Induces Expression of the Toll-Like Receptors (TLRs) 2 and 4 in the Human Peripheral Blood Mononuclear Cells: Implications for Metabolic Inflammation. Cell. Physiol. Biochem. 2019, 53, 1-18. [CrossRef]

52. Wu, Z.; Zhang, Z.; Lei, Z.; Lei, P. CD14: Biology and role in the pathogenesis of disease. Cytokine Growth Factor Rev. 2019, 48, 24-31. [CrossRef] [PubMed]

53. Liu, J.; Li, S.; Sun, D. Calcium Dobesilate and Micro-vascular diseases. Life Sci. 2019, 221, 348-353. [CrossRef] [PubMed]

54. Szmitko, P.E.; Wang, C.H.; Weisel, R.D.; Jeffries, G.A.; Anderson, T.J.; Verma, S. Biomarkers of Vascular Disease Linking Inflammation to Endothelial Activation Part II. Circulation 2003, 108, 2041-2048. [CrossRef] [PubMed]

55. Luttun, A.; Lutgens, E.; Manderveld, A.; Maris, K.; Collen, D.; Carmeliet, P.; Moons, L. Loss of Matrix Metalloproteinase9 or Matrix Metalloproteinase-12 Protects Apolipoprotein E-Deficient Mice Against Atherosclerotic Media Destruction but Differentially Affects Plaque Growth. Circulation 2004, 109, 1408-1414. [CrossRef] [PubMed]

56. Wang, Y.; Li, C.; Zhu, F.; Jin, X. The effect of calcium dobesilate on the formation of atherosclerotic plaques and its mechanism. J. Wezhou Med. Univ. 2020, 50, 387-390.

57. Phorbol Ester-Induced Myeloid Differentiation Is Mediated by Protein Kinase C-Alpha and -Delta and Not by Protein Kinase C-Beta II, -Epsilon, -Zeta, and -Eta-PubMed. Available online: https:/ / pubmed.ncbi.nlm.nih.gov/8376369/ (accessed on 25 October 2021).

58. Activation of Beta-Isozyme of Protein Kinase C (PKC Beta) Is Necessary and Sufficient for Phorbol Ester-Induced Differentiation of HL-60 Promyelocytes. Studies with PKC Beta-Defective PET mutant-PubMed. Available online: https:/ / pubmed.ncbi.nlm. nih.gov / 8308000 / (accessed on 25 October 2021).

59. Chen, B.-C.; Lin, W.W. PKC- and ERK-dependent activation of IкB kinase by lipopolysaccharide in macrophages: Enhancement by P2Y receptor-mediated CaMK activation. Br. J. Pharmacol. 2001, 134, 1055-1065. [CrossRef] [PubMed]

60. Lee, F.S.; Peters, R.T.; Dang, L.C.; Maniatis, T. MEKK1 activates both IkappaB kinase alpha and IkappaB kinase beta. Proc. Natl. Acad. Sci. USA 1998, 95, 9319-9324. [CrossRef]

61. Das, J.; Ramani, R.; Suraju, M.O. Polyphenol compounds and PKC signaling. Biochim. Biophys. Acta Gen. Subj. 2016, 1860, 2107-2121. [CrossRef]

62. Kyaw, M.; Yoshizumi, M.; Tsuchiya, K.; Kirima, K.; Tamaki, T. Antioxidants Inhibit JNK and p38 MAPK Activation but not ERK 1/2 Activation by Angiotensin II in Rat Aortic Smooth Muscle Cells. Hypertens. Res. 2001, 24, 251-261. [CrossRef]

63. Kubo-Murai, M.; Hazeki, K.; Sukenobu, N.; Yoshikawa, K.; Nigorikawa, K.; Inoue, K.; Yamamoto, T.; Matsumoto, M.; Seya, T.; Inoue, N.; et al. Protein kinase C $\delta$ binds TIRAP/Mal to participate in TLR signaling. Mol. Immunol. 2007, 44, $2257-2264$. [CrossRef]

64. Woo, J.-H.; Lim, J.H.; Kim, Y.-H.; Suh, S.-I.; Min, D.S.; Chang, J.-S.; Lee, Y.H.; Park, J.-W.; Kwon, T.K. Resveratrol inhibits phorbol myristate acetate-induced matrix metalloproteinase- 9 expression by inhibiting JNK and PKC $\delta$ signal transduction. Oncogene 2004, 23, 1845-1853. [CrossRef] [PubMed]

65. Park, J.-G.; Oh, G.-T. The role of peroxidases in the pathogenesis of atherosclerosis. BMB Rep. 2011, 44, 497-505. [CrossRef] [PubMed]

66. Son, Y.; Cheong, Y.-K.; Kim, N.-H.; Chung, H.-T.; Kang, D.G.; Pae, H.-O. Mitogen-Activated Protein Kinases and Reactive Oxygen Species: How Can ROS Activate MAPK Pathways? J. Signal Transduct. 2011, 2011, 792639. [CrossRef]

67. Li, L.; Sawamura, T.; Renier, G. Glucose Enhances Human Macrophage LOX-1 Expression. Circ. Res. 2004, 94, 892-901. [CrossRef] 
68. Brunet, J.; Farine, J.C.; Garay, R.P.; Hannaert, P. In vitro antioxidant properties of calcium dobesilate. Fundam. Clin. Pharmacol. 1998, 12, 205-212. [CrossRef] [PubMed]

69. Brunet, J.; Farine, J.-C.; Garay, R.P.; Hannaert, P. Angioprotective action of calcium dobesilate against reactive oxygen speciesinduced capillary permeability in the rat. Eur. J. Pharmacol. 1998, 358, 213-220. [CrossRef]

70. Kim, S.-Y.; Lee, J.-G.; Cho, W.-S.; Cho, K.-H.; Sakong, J.; Kim, J.-R.; Chin, B.-R.; Baek, S.-H. Role of NADPH oxidase-2 in lipopolysaccharide-induced matrix metalloproteinase expression and cell migration. Immunol. Cell Biol. 2009, 88, 197-204. [CrossRef]

71. Sorescu, D.; Weiss, D.; Lassègue, B.; Clempus, R.E.; Szöcs, K.; Sorescu, G.P.; Valppu, L.; Quinn, M.; Lambeth, J.D.; Vega, J.D.; et al. Superoxide Production and Expression of Nox Family Proteins in Human Atherosclerosis. Circulation 2002, 105, 1429-1435. [CrossRef]

72. El Benna, J.; Faust, L.R.P.; Johnson, J.L.; Babior, B.M. Phosphorylation of the Respiratory Burst Oxidase Subunit p47phox as Determined by Two-dimensional Phosphopeptide Mapping: Phosphorylation by protein kinase C, protein kinase A, and a mitogen-activated protein kinase. J. Biol. Chem. 1996, 271, 6374-6378. [CrossRef]

73. Huang, S.-L.; Chen, P.-Y.; Wu, M.-J.; Tai, M.-H.; Ho, C.-T.; Yen, J.-H. Curcuminoids Modulate the PKC $/$ NADPH Oxidase/Reactive Oxygen Species Signaling Pathway and Suppress Matrix Invasion during Monocyte-Macrophage Differentiation. J. Agric. Food Chem. 2015, 63, 8838-8848. [CrossRef]

74. Lee, I.-T.; Shih, R.-H.; Lin, C.-C.; Chen, J.-T.; Yang, C.-M. Role of TLR4/NADPH oxidase/ROS-activated p38 MAPK in VCAM-1 expression induced by lipopolysaccharide in human renal mesangial cells. Cell Commun. Signal. 2012, 10, 33. [CrossRef] [PubMed]

75. Batchuluun, B.; Inoguchi, T.; Sonoda, N.; Sasaki, S.; Inoue, T.; Fujimura, Y.; Miura, D.; Takayanagi, R. Metformin and liraglutide ameliorate high glucose-induced oxidative stress via inhibition of PKC-NAD $(\mathrm{P}) \mathrm{H}$ oxidase pathway in human aortic endothelial cells. Atherosclerosis 2014, 232, 156-164. [CrossRef]

76. Vasamsetti, S.B.; Karnewar, S.; Kanugula, A.K.; Thatipalli, A.R.; Kumar, J.M.; Kotamraju, S. Metformin Inhibits Monocyte-toMacrophage Differentiation via AMPK-Mediated Inhibition of STAT3 Activation: Potential Role in Atherosclerosis. Diabetes 2015, 64, 2028-2041. [CrossRef] [PubMed]

77. Barry-Lane, P.A.; Patterson, C.; Van Der Merwe, M.; Hu, Z.; Holland, S.M.; Yeh, E.T.; Runge, M.S. p47phox is required for atherosclerotic lesion progression in $\mathrm{Apo}^{-/-}$mice. J. Clin. Investig. 2001, 108, 1513-1522. [CrossRef] [PubMed]

78. Gao, X.-P.; Standiford, T.J.; Rahman, A.; Newstead, M.; Holland, S.M.; Dinauer, M.C.; Liu, Q.-H.; Malik, A.B. Role of NADPH Oxidase in the Mechanism of Lung Neutrophil Sequestration and Microvessel Injury Induced by Gram-Negative Sepsis: Studies in p47 ${ }^{\text {hox-l- }}$ and gp91 ${ }^{\text {phox-/- }}$ Mice. J. Immunol. 2002, 168, 3974-3982. [CrossRef]

79. Liu, G.C.; Fang, F.; Zhou, J.; Koulajian, K.; Yang, S.; Lam, L.; Reich, H.N.; John, R.; Herzenberg, A.M.; Giacca, A.; et al. Deletion of p47 phox attenuates the progression of diabetic nephropathy and reduces the severity of diabetes in the Akita mouse. Diabetologia 2012, 55, 2522-2532. [CrossRef]

80. Bey, E.A.; Xu, B.; Bhattacharjee, A.; Oldfield, C.M.; Zhao, X.; Li, Q.; Subbulakshmi, V.; Feldman, G.M.; Wientjes, F.B.; Cathcart, M.K. Protein Kinase C $\delta$ Is Required for $\mathrm{p} 47^{\text {phox }}$ Phosphorylation and Translocation in Activated Human Monocytes. J. Immunol. 2004, 173, 5730-5738. [CrossRef]

81. Lee, H.B.; Yu, M.R.; Song, J.S.; Ha, H. Reactive oxygen species amplify protein kinase C signaling in high glucose-induced fibronectin expression by human peritoneal mesothelial cells. Kidney Int. 2004, 65, 1170-1179. [CrossRef]

82. Wu, W.-S.; Tsai, R.K.; Chang, C.H.; Wang, S.; Wu, J.-R.; Chang, Y.-X. Reactive Oxygen Species Mediated Sustained Activation of Protein Kinase $\mathrm{C} \alpha$ and Extracellular Signal-Regulated Kinase for Migration of Human Hepatoma Cell Hepg2. Mol. Cancer Res. 2006, 4, 747-758. [CrossRef]

83. Chen, C.-L.; Chan, P.-C.; Wang, S.-H.; Pan, Y.-R.; Chen, H.-C. Elevated expression of protein kinase C $\delta$ induces cell scattering upon serum deprivation. J. Cell Sci. 2010, 123, 2901-2913. [CrossRef]

84. Lien, C.-F.; Chen, S.-J.; Tsai, M.-C.; Lin, C.-S. Potential Role of Protein Kinase C in the Pathophysiology of Diabetes-Associated Atherosclerosis. Front. Pharmacol. 2021, 12, 1674. [CrossRef] [PubMed]

85. Koch, A.; Cho, M.; Burrows, J.; Polverini, P.; Leibovich, S.J. Inhibition of production of monocyte/macrophage-derived angiogenic activity by oxygen free-radical scavengers. Cell Biol. Int. Rep. 1992, 16, 415-425. [CrossRef]

86. Nespereira, B.; Pérez-Ilzarbe, M.; Fernández, P.; Fuentes, A.M.; Páramo, J.A.; Rodríguez, J.A. Vitamins C and E downregulate vascular VEGF and VEGFR-2 expression in apolipoprotein-E-deficient mice. Atherosclerosis 2003, 171, 67-73. [CrossRef]

87. Oak, M.-H.; El Bedoui, J.; Schini-Kerth, V.B. Antiangiogenic properties of natural polyphenols from red wine and green tea. J. Nutr. Biochem. 2005, 16, 1-8. [CrossRef] [PubMed] 